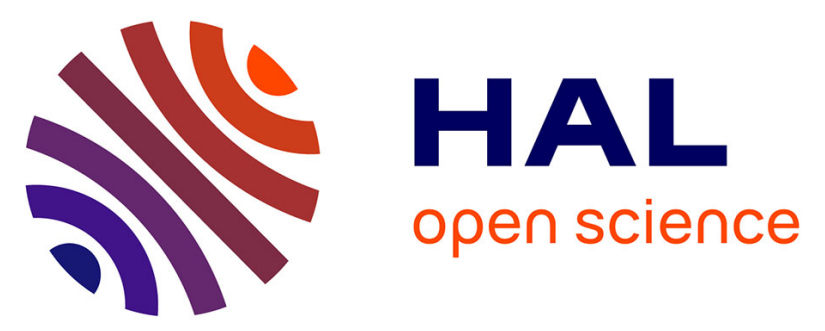

\title{
High PAH degradation and activity of degrading bacteria during alfalfa growth where a contrasted active community developed in comparison to unplanted soil
}

\author{
Amélia Bourceret, Corinne Leyval, Pierre Faure, Catherine Lorgeoux, Aurélie \\ Cebron
}

\section{To cite this version:}

Amélia Bourceret, Corinne Leyval, Pierre Faure, Catherine Lorgeoux, Aurélie Cebron. High PAH degradation and activity of degrading bacteria during alfalfa growth where a contrasted active community developed in comparison to unplanted soil. Environmental Science and Pollution Research, 2018, 25 (29), pp.29556 - 29571. 10.1007/s11356-018-2744-1 . hal-01930927

\section{HAL Id: hal-01930927 \\ https://hal.science/hal-01930927}

Submitted on 13 May 2020

HAL is a multi-disciplinary open access archive for the deposit and dissemination of scientific research documents, whether they are published or not. The documents may come from teaching and research institutions in France or abroad, or from public or private research centers.
L'archive ouverte pluridisciplinaire HAL, est destinée au dépôt et à la diffusion de documents scientifiques de niveau recherche, publiés ou non, émanant des établissements d'enseignement et de recherche français ou étrangers, des laboratoires publics ou privés. 
1 High PAH degradation and activity of degrading bacteria during alfalfa growth where a contrasted active community developed in comparison to unplanted soil

Amélia Bourceret ${ }^{1,2, \S}$, Corinne Leyval ${ }^{1,2}$, Pierre Faure ${ }^{1,2}$, Catherine Lorgeoux ${ }^{3}$, Aurélie Cébron $^{1,2 \dagger}$

${ }^{1}$ Université de Lorraine, LIEC UMR7360, Faculté des Sciences et Technologies, Bd des Aiguillettes, BP 70239, 54506 Vandoeuvre-lès-Nancy, France.

${ }^{2}$ CNRS, LIEC UMR7360, Faculté des Sciences et Technologies, Bd des Aiguillettes, BP 70239, 54506 Vandoeuvre-lès-Nancy, France.

${ }^{3}$ Université de Lorraine, CNRS, CREGU,GeoRessourcesLab.,UMR 7359,Faculté des Sciences et Technologies, Bd des Aiguillettes, BP 70239, 54506 Vandoeuvre-lès-Nancy, France.

${ }^{\S}$ Current affiliation: Department Plant Microbe Interactions, Max Planck Institute for Plant Breeding Research, 50829 Köln, Germany.

'Corresponding author: aurelie.cebron@univ-lorraine.fr; phone: (+33) 383684296

Key words: historically contaminated soil, alfalfa, rhizosphere, RNA, bacterial diversity, PAH-degraders, functional community

\section{Abstract}

PAH biodegradation in plant rhizosphere has been investigated in many studies, but the timescale of degradation and degrading bacteria activity was rarely considered. We explored the impact of plants on the temporal variability of PAH degradation, microbial abundance, activity and bacterial community structure in a rhizotron experiment. A historically contaminated soil was spiked with PAHs, planted or not with alfalfa, over 22 days with sampling once a week. In both conditions, most of the spiked PAHs were dissipated during the first week, conducting to polar polycyclic aromatic compound production and to decreased richness and diversity of bacterial communities. We showed a rapid impact of the rhizosphere on PAH degradation via the increased activity of PAH-degrading bacteria. After 12 days, PAH degradation was significantly higher in the planted (100\% degradation) than in unplanted $(70 \%)$ soil. Gram-negative (Proteobacteria) PAH-dioxygenase genes and transcripts were higher in planted than unplanted soil and were correlated to the spiked PAH degradation. Conversely, Gram-positive (Actinobacteria) PAH-dioxygenase gene transcription was constant over time in both conditions. At 12 days, plant growth favoured the 
activity of many Gamma-Proteobacteria (Pseudomonadaceae, Stenotrophomonas and Acinetobacter) while in unplanted soil Alpha-Proteobacteria (Sphingomonadaceae, Sphingobium and Magnetospirillum) and Actinobacteria (Iamia, Geodermatophilaceae, and Solirubrobacterales) were more active.

\section{Introduction}

Polycyclic Aromatic Hydrocarbons (PAHs) are organic pollutants resulting from coal-related activities (coking plants, gas plants) and derived activities (iron- and steel-production plants). These toxic compounds are persistent in the environment. Their high hydrophobicity, which leads to adsorption to the soil matrix, reduces their bioavailability to microorganisms (Bogan and Sullivan 2003). This aging process decreases PAH bioavailability in soils over time, and slows down the rate of PAH biodegradation (Allard et al. 2000). Microbial diversity also evolves over time, suggesting an adaptation to contamination (Bourceret et al. 2016). Thus, it is essential to better understand the temporal variations in microbial activity, to monitor it, and to relate it to the dynamics of PAHs in soils. To address this, many studies have used soils spiked with model PAH compounds (Allard et al. 2000; Thomas and Cébron 2016), but this makes them more bioavailable and therefore more degradable than aged PAHs in historically contaminated soils. Therefore it is appeared to us more realistic to study the biodegradation of a complex mixture of PAHs so as to investigate the activity of autochthonous microbial populations from aged contaminated soils and involved in biodegradation (Cébron et al. 2013).

Rhizodegradation is a cost-effective and environment-friendly process using microorganisms associated to roots to dissipate soil organic pollutants, such as PAHs (Haritash and Kaushik 2009). Plants release root exudates composed of sugars, amino and organic acids, among other compounds (Walker et al. 2003; Gao et al. 2015). They provide carbon growth sources for microorganisms, and biosurfactant compounds that increase PAH bioavailability and dissipation (Joner et al. 2002; Zhou et al. 2011). In PAH-contaminated soils, root exudates can increase microbial abundance (Kirk et al. 2005) and activity (Cébron et al. 2011). Several studies showed that plants enhanced PAH dissipation by modifying microbial diversity (Kawasaki et al. 2012) and activity (Yergeau et al. 2014; Peng et al. 2015), and selecting PAH degraders (Storey et al. 2014; Siciliano et al. 2003) in the rhizosphere. Consequently, most studies indicated that the combination of all these processes increased PAH degradation in the presence of plants (Liste and Alexander 2000; Tejeda-Agredano et al. 2013) and more 
precisely in the rhizosphere. However, other experiments also evidenced no effect (Gartler et al. 2014), or slower PAH degradation in planted soil as compared to unplanted soil (Thomas and Cébron 2016). These contrasting results could be explained by spatio-temporal variations that occur within the rhizosphere and activate various processes during plant development. This hypothesis justifies further research on the time course of PAH-degradation processes and on the activity of the functional microbial community in soil-plant systems.

The temporal dynamics of rhizospheric processes could explain the variable efficiency of PAH degradation observed with plants. In uncontaminated soil, it has been extensively shown that the composition and quantity of root exudates can vary depending on the plant developmental stage and on root location (Hinsinger et al. 2005; Walker et al. 2003), and can thus modify the microbial community (Yang and Crowley 2000; Hannula et al. 2010; Baudoin et al. 2002), functional diversity (Haichar et al. 2008), and microbial activity (Baudoin et al. 2002). On the other hand, these rhizosphere processes have received little attention in contaminated environments where pollution is an additional factor impacting microorganism activity. It is therefore essential to assess the impact of both PAH pollution and root development on overall microbial activity and on the PAH-biodegrading function to know which factors are the most determining ones in a rhizoremediation context.

Among plant species tested for PAH rhizodegradation, the efficiency of legumes - e.g. alfalfa - is relevant, because they have extensive root systems that allow soil colonization and nutrient uptake (Muratova et al. 2003; D'Orazio et al. 2013). Alfalfa is a plant commonly used in situ during land-farming treatment of organic pollutants (Trapp and Karlson 2001). It is also commonly used in microcosm studies to evaluate rhizodegradation efficiency, and more precisely study the processes involved (Bourceret et al. 2015). A legume such as alfalfa is thus a good and realistic model plant to evaluate the time course of PAH rhizodegradation in aged contaminated soil.

This study aimed to evaluate 1) the dynamics of PAH dissipation in alfalfa rhizosphere as compared to unplanted soil, and 2) the variability of microbial community activity and PAHdegrading bacterial abundance and activity over three weeks of plant growth. We developed a specific 2-compartment rhizotron device to rapidly establish an active root system and put it in contact with PAH spiked soil so as to avoid the time gap between root growth from seeds germination and the degradation of bioavailable pollutants. Rhizotrons were filled with an aged PAH-contaminated soil, initially spiked with a complex mixture of PAHs (i.e. a soil 
organic extract). Rhizotrons were sampled once a week to monitor concentrations of PAHs and potential metabolites (polar polycyclic aromatic compounds, pPAC). Dissolved organic carbon (DOC), $\mathrm{pH}$, and humidity were measured to characterize the rhizosphere and soil conditions. Working on extracted DNA and RNA fractions, we also assessed total bacterial and fungal abundance, PAH-degrading bacterial abundance and transcriptional activity levels. Finally, we assessed active bacterial community structures by pyrosequencing of 16S rRNA transcripts.

\section{Materials and Methods}

\section{Experimental device}

We used an aged PAH contaminated soil, from a former coking plant (Neuves-Maisons (NM), Lorraine, France) to perform rhizotron experiments. Soil characteristics and spiking procedure were described previously by Bourceret et al. (2015). Briefly, the NM soil (1033 $\pm 148 \mathrm{mg}$ per $\mathrm{kg}$ of $\mathrm{dw}$ soil of $\Sigma 13$ PAHs (fluorene, phenanthrene, anthracene, fluoranthene, pyrene, benzo(a)anthracene, chrysene, benzo(b)fluoranthene, benzo(k)fluoranthene, benzo(a)pyrene, dibenzo(a,h)anthracene, benzo(g,h,i)perylene, indeno(1,2,3-cd)pyrene) was air-dried, sieved at $2 \mathrm{~mm}$ and spiked with a complex organic pollutant extract (Table S1), rich in PAHs and obtained from the same soil using chloroform extraction (Cébron et al. 2013). After solvent evaporation, the spiked soil was mixed with NM soil not exposed to chloroform, in a onetenth ratio. Experimental device was divided in two parts (Fig. 1): the top part (minirhizotron) was a poly-methyl methacrylate box (7 cm high x $29.8 \mathrm{~cm}$ long x $2.3 \mathrm{~cm}$ wide) without bottom, that fits into the second part: a rhizotron $(30 \mathrm{~cm}$ high $\times 30 \mathrm{~cm}$ long x $2.5 \mathrm{~cm}$ wide) with a removable front face allowing spatially localized depth sampling as described by Bourceret et al. (2015). First, 8 mini-rhizotrons were filled with NM soil, closed at the bottom by bolting cloth ( $5 \mu \mathrm{m}$ mesh), and adjusted to $80 \%$ of the soil water holding capacity (WHC) (corresponding to $203 \mathrm{ml}$ deionized water per $\mathrm{kg}$ of $\mathrm{dw}$ soil). Alfalfa (Medicago sativa var. Europe) was planted on 4 of these devices by seeding $2.4 \mathrm{~g}$ of seeds (c.a. 26 seeds per $\mathrm{cm}^{2}$ ) and the other 4 devices were left unplanted. After germination, the 8 devices were placed in a plant growth chamber under controlled conditions $\left(22^{\circ} \mathrm{C} / 18^{\circ} \mathrm{C}\right.$ day/night, $80 \%$ relative humidity, c.a. $250 \mu \mathrm{mol}$ photons $\mathrm{m}^{-2} \mathrm{~s}^{-1}, 16$ hours photoperiod) and were maintained at $80 \%$ of the WHC by weighing the devices every two days. The previous growth of plant in NM soil allowed to avoid the delay between time needed for root development and the PAH degradation, that was already shown to be fast in spiked soil with a previous study (Bourceret et al. 2015). After 15 days, when roots reached the bottom of the mini-rhizotron devices, eight 
rhizotrons were filled with spiked NM soil (1418 $\pm 193 \mathrm{mg}$ of $\Sigma 13$ PAHs per $\mathrm{kg}$ of dw soil), bolting cloths of the mini-rhizotrons were removed and devices were fitted in their corresponding rhizotron to allow root penetration and growth in spiked soil. This time corresponded to T0. Initial spiked NM soil was sampled: six aliquots from each of the eight rhizotrons corresponding to $48 \mathrm{~T} 0$ samples were stored at $-80^{\circ} \mathrm{C}$ for further analyses. Then the 4 planted and 4 unplanted devices were incubated in plant growth chamber in conditions described above. After 6 (T1), 12 (T2), 16 (T3) and 22 (T4) days of plant growth, two rhizotrons (one planted and one unplanted) were harvested and opened to allow core sampling using a stainless steel cylinder equipped with a PTFE piston $(1.6 \mathrm{~cm}$ diameter, $2.5 \mathrm{~cm}$ long, thus enabling to collect soil cores of around $5 \mathrm{~cm}^{3}$ ). At $3 \mathrm{~cm}$ from the interface of the two compartments, 6 samples with $3 \mathrm{~cm}$ between the core centers were collected per device (Fig. 1). Soil samples were prepared as previously described by Bourceret et al. (2015). Briefly, after 3 rinsing by sterile water, roots were spread on a black paper and photographed to estimate the size of each root fragment using ImageJ software (http://rsbweb.nih.gov/ij/). Roots were then air-dried at $60^{\circ} \mathrm{C}$ and weighed to quantify dry root biomass. Rhizosphere soil, collected from root rinsing water by centrifugation at $4400 \mathrm{rpm}$ for 10 minutes, and bulk soil were weighed to calculate the ratio between the two fractions and were mixed together to obtain a unique soil sample stored at $-80^{\circ} \mathrm{C}$ before analyses: soil characteristics (pH, DOC, organic acids, and sugar concentrations), $\mathrm{PAH}$ and pPAC concentrations, and DNA/RNA extractions. Soil humidity was measured by collecting 3 other samples on the side of the rhizotrons and by weighing the soil before and after drying at $60^{\circ} \mathrm{C}$ for 48 hours.

\section{Soil characteristics}

Soil solutions were prepared with $1 \mathrm{~g}$ of soil in distilled water (1:5 w/v ratio), and $\mathrm{pH}$ was measured using a pH-meter electrode (BioBlock scientific, pHM210 Radiometer analytical). After centrifugation $\left(10 \mathrm{~min}, 4000 \mathrm{rpm}, 20^{\circ} \mathrm{C}\right)$ supernatant was filtered $(0.45 \mu \mathrm{m})$ and diluted 20 times to quantify dissolved organic carbon (DOC) with a total organic carbon analyzer (TOC-V CSH, Shimadzu). Sugars (inositol, trehalose, sucrose, glucose, fructose) and organic acids (formate, butyrate, oxalate) were quantified from non-diluted extract with an ionexchange chromatograph ICS 5000 (CarboPac SA10 column, 40 ${ }^{\circ} \mathrm{C}$ ) and ICS 3000 (AS 11$\mathrm{HC}$ column, $35^{\circ} \mathrm{C}$ ), respectively.

\section{Extraction and quantification of total PAHs, pPACs and bioavailable PAHs}

An aqueous solution of hydroxypropyl- $\beta$-cyclodextrin $(20 \mathrm{ml}, 50 \mathrm{mM}$ ) (Acros organics, New Jersey, USA) was used to extract available PAH fraction from $1 \mathrm{~g}$ of fresh soil from $5 \mathrm{NM}$ 
soil samples before spiking, 6 T0 samples, and 48 rhizotron samples (6 samples from both planted and bare rhizotrons at each sampling time) in Oak Ridge Centrifuge tubes (FEP, Nalgene, USA) (Reid et al. 2000). After stirring (100 rpm) for 16 hours at $24{ }^{\circ} \mathrm{C}$ and 2 centrifugation steps $(10000 \mathrm{rpm}, 20 \mathrm{~min})$, dichloromethane was added $(24 \mathrm{ml})$ to the aqueous supernatant (c.a. $30 \mathrm{ml}$ ) to extract available PAHs. An Accelerated Solvent Extractor (ASE350 Dionex ${ }^{\circledR}$ ) was used to extract total PAHs and pPACs with dichloromethane $\left(130^{\circ} \mathrm{C}, 100\right.$ bars) from $0.25 \mathrm{~g}$ of soil (stored at $-80^{\circ} \mathrm{C}$ ) from $12 \mathrm{NM}$ soil samples before spiking, 48 T0 samples, and 48 rhizotron samples previously lyophilized and crushed $(<500$ $\mu \mathrm{m})$. Dichloromethane extracts were split in two fractions to quantify PAHs using HPLC/UVFluo (High Pressure Liquid Chromatography) and pPACs using GC-MS (gas chromatography coupled to mass spectrometry). Firstly, the two dichloromethane extracts containing available and total PAHs were evaporated under nitrogen flow and diluted in $5 \mathrm{ml}$ and $20 \mathrm{ml}$ of acetonitrile, respectively. HPLC (Dionex Ultimate 3000) system, with a 100-mm long and 4.6-mm internal diameter separation column (SupelcoAscendis Express C10), 2.6-mm granulometry allowed quantifying PAHs from $10 \mu \mathrm{l}$ of extract. From total and available extracts, 13 PAHs (16 US-EPA PAHs excluding the three more volatile molecules: naphtalene, acenaphtylene and acenaphtene) were quantified by using a UV (254 nm) and a fluorescence detector, respectively. Secondly, from dichloromethane extracts pPACs were quantified on a GC-6890 (Agilent Technologies) equipped with a DB5- MS column (60 $\times$ $0.25 \mathrm{~mm}$ id $\times 0.25 \mu \mathrm{m}$ film thickness) coupled to a MS-5973 Inert (Agilent Technologies) operating SIM mode (Single Ion Monitoring). The oven temperature program was as follows: 2 minutes at $70{ }^{\circ} \mathrm{C}$, then from $70{ }^{\circ} \mathrm{C}$ to $130{ }^{\circ} \mathrm{C}$ at $15^{\circ} \mathrm{C} \min ^{-1}$, then from $130{ }^{\circ} \mathrm{C}$ to $315^{\circ} \mathrm{C}$ at 4 ${ }^{\circ} \mathrm{C} \min ^{-1}$ and then a $25 \mathrm{~min}$ hold at $315^{\circ} \mathrm{C}$. The carrier gas was helium at $1.4 \mathrm{ml} \mathrm{min}{ }^{-1}$ constant flow. Fifteen pPACs including 11 oxygenated pPACs (O-PACs) and 4 nitrogenated pPACs (heterocyclic PACs containing nitrogen N-PACs) were quantified by an internal calibration using deuterated internal standards (the list of the 15 quantified polar PAC is given in Hanser et al. (2015). During a sequence, calibration controls were injected every 12 samples to check the overall calibration.

\section{DNA/RNA extraction}

Nucleic acids were extracted from $0.5 \mathrm{~g}$ of soil using a FastDNA SPIN Kit for soil (MP Biomedicals, France). DNA and RNA were co-extracted from the same aliquots of samples stored at $-80^{\circ} \mathrm{C}$. DNA was resuspended in $100 \mu \mathrm{l}$ of DES (Dnase-free water) and quantified at $480 \mathrm{~nm}$ (Xenius, SAFAS) by using Quant-iTPicoGreenasDNA Assay kit (Invitrogen), and 
then extracts were diluted to $2 \mathrm{ng} / \mu \mathrm{l}$ before amplification. RNA was collected from the filtrates at the DNA binding to the column step. After sodium acetate (0.1Vol, $3 \mathrm{M}, \mathrm{pH} 5.2)$ and isopropanol precipitation for one night at $4{ }^{\circ} \mathrm{C}$ and centrifugation, RNA was resuspended in $45 \mu \mathrm{l}$ of Rnase-free water. Two steps of DNase (Thermo scientific) treatment (addition of $10 \mu 1$ of DNase buffer $(10 \mathrm{X}), 1 \mu \mathrm{l}$ of DNase $(1 \mathrm{u} / \mu \mathrm{l})$ and incubated 1 hour at $\left.37^{\circ} \mathrm{C}\right)$ and purification using RNeasyMinElute Cleanup kit (Qiagen) allowed obtaining $30 \mu 1$ of pure extract (presence of DNA contamination was PCR checked). After quantification at $480 \mathrm{~nm}$ (Xenius, SAFAS) by Quant-iTRiboGreen RNA Assay kit (Invitrogen), extracts were converted in cDNA using SuperScript III First-Strand kit (Invitrogen). Reverse transcription reaction $(20 \mu \mathrm{l})$ was performed using $1 \mu \mathrm{l}$ of random hexamer $(50 \mathrm{ng} / \mu \mathrm{l}), 1 \mu \mathrm{l}$ of hybridization buffer and $22.27 \mathrm{ng}$ of RNA ( $5 \mathrm{~min}$ at $65^{\circ} \mathrm{C}$ and $1 \mathrm{~min}$ on ice), then $10 \mu \mathrm{l}$ of reaction buffer (2X) and $2 \mu \mathrm{l}$ of enzyme mix were added and incubated $10 \mathrm{~min}$ at $25^{\circ} \mathrm{C}, 50 \mathrm{~min}$ at $50^{\circ} \mathrm{C}$ and 5 $\min$ at $85^{\circ} \mathrm{C}$.

\section{Real-time PCR quantification}

The primer sets Fung5F/FF390R (Lueders et al. 2004; Thion et al. 2013), 968F/1401R (Felske et al. 1998; Cébron et al. 2008) and PAH-RHD $\alpha$ GN F/R, PAH-RHD ${ }_{\alpha}$ GP F/R (Cébron et al. 2008), targeting the fungal 18SrRNA genes, the bacterial 16S rRNA genes, and the PAH-ring hydroxylating dioxygenase genes from Gram-negative and Gram-positive bacteria, respectively, were used to quantify by real-time PCR the abundance of active and total fungal, bacterial and PAH-degrading bacterial populations. Amplification reactions were performed on $20 \mu \mathrm{l}$ of reaction mix containing $10 \mu \mathrm{l}$ of iQ SYBR green SuperMix (Bio-Rad), $0.8 \mu \mathrm{l}$ of each primer $(10 \mu \mathrm{M}), 0.4 \mu \mathrm{l}$ of $3 \%$ BSA (bovine serum albumin) solution, $0.2 \mu \mathrm{l}$ of DMSO (dimethyl sulfoxide), $0.08 \mu \mathrm{l}$ of T4 bacteriophage gene 32 product (MP Biomedicals, France) and $1 \mu 1$ of diluted gDNA or pure cDNA. Amplification and quantification were achieved using a CFX96 Real-Time PCR detection system (Bio-Rad) according to standard plasmid dilution series and program described by Cébron et al. (2008) and Thion et al. (2012). After soil humidity correction, data were expressed in number of gene copies per gram of dry weight soil, in percentage of transcripts relative to gene copies, and in percentages of $18 \mathrm{~S}$ rRNAor PAH-dioxygenase relative to $16 \mathrm{~S}$ rRNA gene or transcript copies.

\section{Pyrosequencing and sequence analysis}

The primer set 515F ((5'-GTG CCA GCM GCC GCG GTA A-3') / 907R (5'-CCG TCA ATT CMT TTR AGT TT-3')) (Turner et al. 1999) was used to amplify the V4-V5 region of bacterial 16S rDNA from gDNA and cDNA. Samples were identified with a MID (Multiplex 
IDentifier, Roche). PCR reactions were achieved as described in Bourceret et al. (2016). Beckman Coulter Genomics (Danvers, MA, USA) sequenced libraries using a 454/Roche GSFLX Titanium system. Data were deposited in the NCBI Sequence Read Archive (SRA) under the BioProject ID: PRJNA324193. Denoised 16S rDNA sequenced were analysed in QIIME 1.8.0 pipeline (Caporaso et al. 2010) as previously described by Bourceret et al. (2017). Briefly, after filtering and reverse complement non-sense sequences, data from gDNA and cDNA were gathered and clustered in Operational Taxonomic Units (OTUs) at 97\% of similarity and their representative sequences were affiliated at different taxonomic levels (from phyla to genus) using RDP classifier (Wang et al. 2007) and the Greengenes 13_5 database (McDonald et al. 2012). Then subsampling was performed to the lowest number of sequences counted in one of the samples (4,739 sequences per sample) and alpha-diversity indexes (richness and diversity estimates) were calculated using QIIME 1.8.0 pipeline.

\section{Statistical analyses}

Statistical analyses were performed using XLStat 2013 software (Addinsoft). One-way analysis of variance (ANOVA, with $\mathrm{p}<0.05$ ) followed by a Newman-Keuls multiple comparison test was performed to measure the time effect in each condition (planted and unplanted) between 0 and 22 days. Two-way analysis of variance (ANOVA, with $p<0.05$ ) followed by a Newman-Keuls multiple comparison tests were performed to measure the time and plant effect between T1 and T4. Box plots were drawn using PAH data to compare their distribution and variability. Significant differences in relative abundance of dominant OTUs ( $\geq 1 \%$ in at least one sample) over time, were identified in cDNA samples with STAMP version 2.0.8 (Parks and Beiko 2010) by a Tukey Kramer ANOVA, with a Benjamini Hochberg correction of $p$ value $(q<0.05$ and Effect size $(E S)>0.26)$. Significant differences in the ratio cDNA/gDNA OTU abundance, according to the presence of plant was studied by Student-t test with a Benjamini Hochberg correction of $\mathrm{p}$ value with the differential expression function in XLStatOmics package. Canonical correspondence analysis (CCA) followed by a Monte Carlo permutation test (1000 permutations) was performed by using XLStat-ADA 2015 software (Addinsoft) to study, considering both conditions (alfalfa and unplanted soil) and 4 sampling times (0,6, 12, 16 and 22 days), relationship between the relative abundance of the 41 most abundant OTUs ( $\geq 1 \%$ in at least one sample) and environmental variables (root biomass and length, $\mathrm{pH}$, percentage of Gram-negative and Gram-positive PAH dioxygenase transcripts and genes, sugars, organic acids, and PAH content). 


\section{Results}

\section{Rhizosphere parameters}

Humidity stayed constant (around $80 \%$ of the WRC) over time in both planted and unplanted soil rhizotrons but was globally significantly higher in unplanted soil (78.36 \pm 20.91 and $70.85 \pm 9.98 \%$, in unplanted and alfalfa planted soil, respectively). In alfalfa rhizotron, root biomass was significantly $(\mathrm{p}<0.05)$ higher after 22 days of plant development than after 6 days, whereas root length significantly increased over time and was significantly different between 6 and 12 days and then between 16 and 22 days (Fig. 2A). Related to the plant growth, several parameters, highlighting the effect of root exudation on soil properties, increased over time. Globally sugar concentration and DOC increased significantly over time in the planted compared to unplanted soil. Indeed sugar concentration was significantly higher after 12 days in planted than in unplanted soil where no sugar was detected (Fig. 2B) and DOC stayed constant over time in both rhizotrons until the $16^{\text {th }}$ day, and then increased significantly in planted soil on the $22^{\text {nd }}$ day (Fig. 2C). At this time point, organic acids were detected in alfalfa planted rhizotron $\left(0.21 \pm 0.13 \mathrm{mg} \cdot \mathrm{kg}^{-1}\right)$ but none in unplanted soil. Surprisingly soil $\mathrm{pH}$ increased significantly over time in both conditions and was stable after 12 days. However it increased more rapidly in the planted than in the unplanted soil rhizotron with a significant difference at 6 days (Fig. 2D).

\section{PAHs and pPACs contents}

The total aged PAH concentration ( $\Sigma 13$ PAHs) of the NM soil $\left(1033 \pm 148 \mathrm{mg} \cdot \mathrm{kg}^{-1} \mathrm{dw}\right.$ soil $)$ was significantly increased $(\mathrm{p}<0.05)$, i.e $27 \%$, after soil spiking with the organic pollutant extract and reached $1418 \pm 193$ mg.kg.dw soil ${ }^{-1}$ at the beginning (T0) of the experiment (Fig. 3). The bioavailable PAH fraction was also increased by $41 \%$ and reached $63.7 \pm 18.0 \mathrm{mg} . \mathrm{kg}^{-}$ ${ }^{1} \mathrm{dw}$ soil, while it represented $37.3 \pm 15.6 \mathrm{mg} \cdot \mathrm{kg}^{-1} \mathrm{dw}$ soil before spiking (data not shown). Spiking increased the concentration in total and bioavailable fractions of most of the $13 \mathrm{PAH}$ compounds (Fig. S1). The total PAH concentration decreased significantly between 0 and 6 days and stayed constant until the $22^{\text {nd }}$ day in both planted and unplanted rhizotrons (Fig. 3). From the $6^{\text {th }}$ days, the total PAH concentration dropped down to $1200 \pm 210$ and $1024 \pm 190$ mg.kg.dw soil ${ }^{-1}$ in unplanted and planted soil, respectively, corresponding to a decrease in 19 and $24 \%$ relative to the initial concentration, and to 70 and $100 \%$ of the spiked PAH fraction, respectively. The concentration in total PAHs was significantly lower in alfalfa than in unplanted soil when considering all times together (from 6 to 22 days, two-way ANOVA) and was mostly explained by a significant difference after 12 days (Student t-test) of incubation 
(Fig. 3). The concentrations of several compounds decreased significantly from the $6^{\text {th }}$ day (fluorene, phenanthrene, fluoranthene, pyrene, benzo(k)fluoranthene, benzo(a)pyrene and benzo(g,h,i)perylene only in planted condition)whereas the concentration of other PAHs remained constant over the time course (anthracene, benzo(a)anthracene, chrysene, benzo(b)fluoranthene, dibenzo(a,h)anthracene, indeno(1,2,3-cd)pyrene)) or even increased significantly (benzo(g,h,i)perylene) from the $22^{\text {nd }}$ day, in presence of plant (Fig. S2). Bioavailable PAH fraction decreased also significantly between $\mathrm{T} 0$ and the $6^{\text {th }}$ day in both conditions, reaching $0.05 \pm 0.01$ and $0.08 \pm 0.03 \mathrm{mg} \cdot \mathrm{kg}^{-1} \mathrm{dw}$ soil, corresponding to ca. $100 \%$ decreases, for both planted and unplanted soil rhizotron. After one week, the bioavailable PAH fraction was significantly lower than in the soil before spiking. Ten oxygenated and one nitrogenous pPAC compounds were detected in initial soil (T0) and in both conditions after 6 days (Table 1). After 6 days the concentration of 4 oxygenated pPAC (methylanthracene9,10-dione, benzoanthracenedione, napthacene-5,12-dione) was significantly higher than at T0, without significant differences between planted and unplanted soils. Benzo(cd)pyrenone was only significantly higher at 6 days than at T0 in the planted rhizotron. The concentration of the other pPAC stayed constant over the first week for both planted and unplanted soils.

\section{Microbial communities}

\section{Abundance of active and total microbial communities}

Bacterial abundance was higher than fungal, and bacteria were also more active over time in both planted and unplanted soil (mean value of $7.84 \times 10^{8} \pm 6.64 \times 10^{8} 16 \mathrm{~S}$ rRNA gene copies and $1.12 \times 10^{10} \pm 1.25 \times 10^{10}$ transcript copies $\mathrm{g} \mathrm{dw}$ soil $^{-1}$ ) while fungi were 100 times less represented (mean value of $9.94 \times 10^{6} \pm 7.04 \times 10^{6} 18 \mathrm{~S}$ rRNA gene copies and $2.05 \times 10^{8} \pm$ $1.48 \times 10^{8}$ transcript copies g dw soil ${ }^{-1}$ ) (Fig. 4A, B). Abundance of $16 \mathrm{~S}$ rRNA genes tended to increase over time in alfalfa and stayed constant in unplanted rhizotron whereas number of 16S rRNA transcripts increased significantly between T0 and the $6^{\text {th }}$ day for both rhizotrons and then stayed constant. Abundance of 16S rRNA genes and transcripts was significantly higher in planted than unplanted rhizotron and plant effect was mainly detected at 12 (T2) and 22 days (T4). Abundance of 18S rRNA genes and transcripts tended to be constant in both unplanted and planted rhizotrons and no plant effect was observed.

Abundance of Gram-negative PAH-dioxygenase genes and transcripts increased significantly between T0 and the $6^{\text {th }}$ day in both rhizotron types, and were higher in planted than in unplanted soils, with a significant plant effect after 12 days (Fig. 4A and B). Abundance of Gram-positive PAH-dioxygenase genes slightly increased over time whereas transcripts 
largely increased between T0 and 6 days in both soil and further increased in planted soil till 12 days, resulting in a higher content in planted than in unplanted rhizotron, significant at each sampling time. The level of PAH-dioxygenase gene transcription was expressed by the ratio of the number of transcripts relative to corresponding gene copies (Fig. 4C). The level of PAH-dioxygenase gene transcription was significantly higher in alfalfa than in unplanted soil specifically after 12 days, and then decreased (for Gram-negative bacteria) and stayed constant (for Gram-positive bacteria) over time without significant differences with unplanted soil (Fig. 4C).

\section{Richness, evenness and diversity of the active community}

Globally, bacterial richness (Chao1) and diversity (Inverse of Simpson's) indices were significantly higher in unplanted than in alfalfa planted rhizotron (Table 2). This difference was significant after 16 days for richness and 12 days for diversity index (Table 2). No significant impact of plant was detected on the bacterial community evenness. For both studied conditions, bacterial richness, diversity and evenness indices decreased significantly during the 6 first days and after this time point increased significantly over time.

To explore the potential bacterial population involved into the rapid PAH degradation appearing at the beginning of the incubation period, we looked for bacterial community structure modification over time (Fig. 5). Among the active community, 12 phyla were identified and their proportion changed over time. In both rhizotrons, Proteobacteria was the more active phylum all over the incubation to the detriment of Chloroflexi, Actinobacteria and Nitrospirae that represented a lower proportion of the active community along the time course compared to the T0. Activity of Beta- and Gamma-Proteobacteria increased between 0 and 6 days and stayed constant or decreased until the end of incubation while the proportion of active Alpha-subdivision members further increased. An opposite trend was observed for the activity of Planctomycetes, Acidobacteria and Delta-Proteobacteria that was first repressed between 0 and 12 days and then favored at the end of the incubation (Fig. 5). The relative abundance of some active phyla evolved also differently over time according to the presence of alfalfa. In alfalfa planted rhizotron, Bacteroidetes and TM6 were more and less active over time, respectively, while the activity of Unclassified Proteobacteria was transiently high and then low over the 22 days. In planted soil, 3 OTUs affiliated to BetaProteobacteria (Thiobacillus, and Un.Oxalobacteraceae), 1 OTU affiliated to AlphaProteobacteria (Mycoplana) and 1 OTU affiliated to Firmicutes (Bacillus selenatarsenatis) were significantly more abundant among the active community after 6 days of incubation than 
at all other times, contrary to the unplanted rhizotron where no OTU was favored after 6 days (Fig. S3). After 12 days of incubation, three other OTUs belonging to Alpha- (Sphingobium), Beta- (Janthinobacterium) and Gamma- (PYR10d3) Proteobacteria were favored in planted soil. In unplanted rhizotron, 5 OTUs affiliated to Alpha- (Mycoplana, Phenylobacterium) and Beta- (Thiobacillus, unclassified. Comamonadaceae) Proteobacteria were significantly more abundant among the active community after 12 days of incubation.

Significant positive or negative impact of plants on shaping active bacterial community was observed on 7 and 18 OTUs after 6 and 12 days of incubation, respectively (Fig. 6). After 6 days, the activity ratio between 16S rRNA and rDNA for 3 OTUs belonging to Gamma(Pseudomonadaceae), Beta-(Achromobacter) Proteobacteria and Firmicutes (Paenibacillus) was significantly higher in alfalfa planted than in unplanted soil. Four other OTUs, affiliated to Alpha- (Un. Sphingomonadaceae), Beta- (Un. Burkolderiales) Protebacteria and Actinobacteria (Un. Micrococcaceae) were more actives in unplanted soil. After 12 days, plant growth favored significantly the activity of 11 OTUs belonging to Alpha- (Devosia), Beta- (Methylophilaceae), Gamma-(Pseudomonadaceae, Stenotrophomonas, Acinetobacter) Proteobacteria, Bacteroidetes (Dyadobacter) and Actinobacteria (Un. Micrococcaceae). In unplanted soil the activity of 6 OTUs affiliated to Alpha-Proteobacteria (Un. Sphingomonadaceae, Sphingobium, Magnetospirillum) and Actinobacteria (Un. Solirubrobacterales, Un. Geodermatophilaceae) was significantly higher than in alfalfa planted soil. After 16 and 22 days of incubation, $56 \%$ and $76 \%$ of the OTUs whose activity is significantly impacted by the presence of plant, were more active in alfalfa planted rhizotron (Fig. S4).

\section{Multivariate analysis}

The two first axes of the canonical correspondence analysis (CCA) explained $62.5 \%$ of bacterial diversity variability among samples (Fig. 7A and B). The F1 axis (explaining 41.8\% of the variability) separates samples from the T0 (located on the right) to all other sampling times. The F2 axis (explaining $20.8 \%$ of the variability) separates samples according to the presence of plant and time, with 6to 22 day samples from the bottom to the top. Alfalfa planted samples were separated from unplanted soil samples according to sugar and DOC contents, root development (biomass and length), abundance of Gram-negative PAHdioxygenase genes and transcripts, and abundance of Gram-positive PAH-dioxygenase transcripts (Fig. 7A). These parameters are correlated to the higher activity of 11 bacterial OTUs, most belonging to Proteobacteria except one Bacteriodetes (Dyalobacter), in the 
alfalfa planted rhizotron (Fig. 7B). These OTUs gathered bacteria affiliated to Pseudomonadales (Acinetobacter and Pseudomonas), Sphingomonadales (Sphingobium), Burkolderiales (Janthinobacterium and Achromobacter) and Rhizobiales (Un.

400

401

402

403

404

405

406

407

408

409

410

411

412 Methylobacteriaceae) orders. Unplanted soil samples were mostly discriminated according to the higher PAH content ( $\sum 13$ PAHs and 2-3, 4 and 5-6 cycles). According to the Pearson correlation matrix (Table S2), $\mathrm{pH}$ and the root biomass and length were positively and significantly correlated to the percentage of Gram-positive PAH-dioxygenase transcripts contrary to the abundance of $18 \mathrm{~S}$ transcripts, showing a negative correlation. Moreover concentrations of 2-3, 4- rings and $\sum 13 \mathrm{PAHs}$ were significantly and negatively correlated to the percentage of Gram-negative PAH-dioxygenase transcripts, shown as the most active degrading community at the beginning of the monitoring.

\section{Discussion}

\section{Rapid PAH dissipation in a spiked aged-contaminated soil}

After 6 days of incubation 100 and $70 \%$ of the spiked PAH fraction was dissipated in the planted and unplanted rhizotrons, respectively. A similar rapid dissipation, of bioavailable PAHs after a few days was previously observed in simplified sand or soil microcosms spiked with phenanthrene (Louvel et al. 2011; Cébron et al. 2011), but never observed with such a complex PAH contaminant mixture. We evidenced the degradation of almost all spiked PAHs including fluorene, phenanthrene, fluoranthene, pyrene, benzo(k)fluoranthene and benzo(a)pyrene (which have from 2 to 5 aromatic cycles) in both conditions. In the same soil (NM) incubated in bioslurry, 30 to $55 \%$ of the aged PAH compounds (fluorene, phenanthrene, fluoranthene, pyrene, benzo(a)anthracene and chrysene) were degraded after 1.5 months of incubation (Biache et al. 2017), indicating the presence of a very effective microbial community for the degradation of a wide range of PAH compounds. Degradation of PAHs by microbial consortia and co-metabolism are often described as playing crucial roles the in degradation of PAH mixtures in the environment (Ghosal et al. 2016) because the presence of low-molecular-weight PAHs could have a synergistic effect on the degradation of more recalcitrant compounds (Van Herwijnen R et al. 2003; Roy et al. 2013). During the first 6 days of the experiment, spiked PAHs were probably the main available carbon sources in both the planted and unplanted rhizotrons, as no increase in DOC or sugar content was observed in either condition. As the microbial community of the aged-contaminated NM coking plant soil was well adapted to PAH pollutants (Cébron et al. 2009; Bourceret et al. 2016), the bacterial 
community was rapidly activated, and the spiked PAH fraction was in turn rapidly biodegraded. The main parameter that limited the biodegradation of aged PAHs in this soil was their low bioavailability (Cébron et al. 2013) andspiking transiently led to more easily biodegradable PAHs. In our experiment, before being irreversibly adsorbed to soil mineral or organic materials, such as clay, black carbon or coal-tar substances (Ghosal et al. 2016), PAHs were rapidly degraded, proving that their availability is crucial for biodegradation. Besides PAH degradation, oxygenated polar compounds (pPAC) were produced during the first week of the experiment. This kind of bioavailable compounds, previously described in water from industrial wasteland (Rollin et al. 2005; Lundstedt et al. 2006) and in coal tar (Northcott and Jones 2001; Benhabib et al. 2010), could result from biotic PAH degradation. Lundstedt et al. (2007) indeed described the production of oxygenated compounds during microbial biodegradation, with apparent concentrations resulting from the balance between pPAC degradation and pPAC production during PAH biodegradation (Biache et al. 2017). The production of oxygenated pPAC possibly more available and more toxic than parent molecules could contribute to shape the bacterial community structure.

Together with PAH biodegradation, we observed that bacterial community abundance and activity rapidly increased during the first 6 days of incubation. Moreover the community composition was drastically modified in both planted and unplanted conditions. Most of bacterial OTUs with increasing activity were affiliated to Beta- and Gamma-Proteobacteria, at the expense of Actinobacteria whose proportions fell sharply. PAH amendment may have caused a shift of bacterial communities from oligotroph, K-strategist, Gram-positive bacteria (such as Actinobacteria) to copiotroph, r-strategist, Gram-negative bacteria (such as Proteobacteria) (Bevivino and Dalmastri 2017). These Proteobacteria are potentially Gramnegative PAH-degraders. We did find a predominance of bacteria known to be involved in PAH degradation, such as OTUs affiliated to the Achromobacter, Janthinobacterium, Pyr10d3, Sphingobium, and Thiobacillus genera and Sphingomonadaceae, Microccocaceae, and Comamonadaceae families (Fernández-Luqueño et al. 2011; Kunihiro et al. 2013). The abundance and transcription level of PAH-dioxygenase genes increased significantly during the first 6 days in both conditions, confirming the higher potential of PAH bacterial degradation. Greater activity of Gram-negative than Gram-positive (Actinobacteria) PAH degraders was evidenced during these early days, indicating that Proteobacteria were most probably the main phylum involved in the biodegradation of the spiked PAHs. This finding was also supported by a higher activity of Proteobacteria as compared to other taxa in both planted and unplanted soils, and by a negative correlation between the activity of Gram- 
negative PAH-degrading bacteria and PAH contents. Several studies indicated that PAH contamination induces a selection of and an enrichment in PAH degraders (Cébron et al. 2008; Zhang et al. 2013; Sawulski et al. 2014), and also up-regulates the transcription of the PAH-dioxygenase gene in pure culture (Kim et al. 2006) or complex communities (Louvel et al. 2011). A negative correlation between the transcription of PAH-dioxygenase genes of Gram-negative bacteria and PAH contents would confirm the major involvement of this population in early pollutant degradation, although we cannot rule out the involvement of Gram-positive Actinobacteria that could be the main active PAH-degraders after PAH spiking (de Menezes et al. 2012). Furthermore, fungi could also be involved in PAH degradation (Cerniglia and Sutherland 2010), but we did not detect any increase of fungal 18S rRNA gene or transcript copies during incubation in either condition, suggesting a fairly limited involvement of these microorganisms in our soil.

\section{Plant effect}

The presence of plants induced a shift in the active bacterial community structure and the PAH-degrading population. The timescale of the experiment (22 days) allowed us to monitor the root development of alfalfa, and compare processes between planted and unplanted soils. In addition to increasing the PAH biodegradation capacity, alfalfa plants globally increased the abundance and activity of bacteria, the abundance of Gram-negative PAH-degrading bacteria and the expression of both Gram-negative and Gram-positive PAH-dioxygenase genes. However, the presence of plants led to a decrease of the bacterial richness and diversity indexes. This finding contrasts with previous observation from the same soil (NM) spiked with phenanthrene and planted with ray-grass. The authors found that plants indeed induced an increase of bacterial species richness and slightly inhibited phenanthrene degradation, even if the abundance of PAH-dioxygenase genes increased, yet without modification of the transcription level as compared to unplanted soil (Thomas and Cébron 2016). These contrasting results can be explained by two different types of contamination, i.e. a PAH mixture $v s$. phenanthrene, and two different plant species with contrasted root systems and root exudation (Bourceret et al. 2015). Root exudates probably partly inhibit the degradation of one sole PAH compound, while they might help in co-metabolism processes when PAH contamination is complex and contains high-molecular-weight compounds (Rentz et al. 2005) as shown for PCB degradation (Vrchotová et al. 2013).

After 6 days, even if root biomass and length were low, the presence of alfalfa had already modified a few parameters. The $\mathrm{pH}$, the abundance and proportion of active Gram-negative 
PAH-degrading bacteria were significantly higher in the planted rhizotron than in the unplanted one. Similar findings about PAH-degrading bacterial activity were reported in batch experiments with sand spiked with phenanthrene (Louvel et al. 2011). After 6 days, plants had already shaped the bacterial community structure: several OTUs belonging to Betaand Gamma-Proteobacteria were significantly more active in the planted rhizotron, while other OTUs belonging to Alpha-, Beta-Proteobacteria and Actinobacteria were favoured in the unplanted rhizotron. In our experiment, after 12 days, root length and sugar content were significantly higher than after 6 days, and root biomass and DOC tended to increase, suggesting a stronger rhizosphere effect. At this sampling time, significantly higher PAHdegradation was observed in the planted rhizotron than in the unplanted one. This could be linked to an increasing level of PAH-dioxygenase transcription in both Gram-negative and Gram-positive PAH-degrading bacterial populations that was significantly higher in the planted soil than in the unplanted one. Our results clearly show a positive and rapid impact of the rhizosphere on the PAH degradation potential via the increased activity of a wider diversity (both GN and GP) of PAH-degrading bacteria. Even if Actinobacteria were enriched in the unplanted soil, the activity of the PAH degraders belonging to this phylum was favored in the rhizosphere. The higher activity of Gram-positive PAH degraders could help in the degradation of more recalcitrant PAH compounds (Kanaly and Harayama 2000). We highlighted a time-dependent effect in the course of the process dynamics, which could explain why some authors did not observe an increase in the activity of PAH-degrading populations in certain rhizospheres (Kawasaki et al. 2015). The addition of artificial root exudates can increase the density of soil PAH degraders, with an increase (Joner et al. 2002) or no difference (Cébron et al. 2011) in the degradation of spiked PAHs. We showed the activity of growing roots in a more natural rhizosphere system. A rhizotron device is probably the most adapted laboratory system to study the dynamics of rhizosphere processes because it makes it possible to perform analyses on precisely located samples with specific characteristics (depth, root density, roots age...) instead of mean rhizosphere samples usually obtained from pot experiments. Rhizotrons can allow studying the root turnover (Leigh et al. 2002), the isothiocyanate degradation rate, microbial communities (Rumberger and Marschner 2003) or spatial heterogeneity of PAH degradation and microbial communities (Bourceret et al. 2015).

In our study, the carbon released by actively growing roots and also leached from the top part of the device presenting a higher root density may have activated PAH degradation through co-metabolism (Ambrosoli et al. 2005). This phenomenon could also be attributed to a 
532 priming effect, whereby the release of labile carbon stimulates microbial density and activity 533 (Haichar et al. 2014), promoting PAH degradation or biotransformation (Rentz et al. 2005). As shown by the canonical analysis the higher differentiation between the planted and unplanted conditions was observed after 6 and 12 days of incubation. Root growth seemed to activate bacterial population mostly belonging to Proteobacteria, such as OTUs affiliated to the Gamma- (Pseudomonadaceae, Stenotrophomonas and Acinetobacter), Alpha(Sphingobium, Devosia), and Beta-(Methylophilaceae, janthinobacterium and Achromobacter) subdivisions. In addition to their ability to degrade PAHs (FernándezLuqueño et al. 2011; Tauler et al. 2015; Gupta et al. 2015), OTUs affiliated to Proteobacteria can be favoured in the presence of plants as compared to unplanted soil (Thomas and Cébron 2016; Thomas et al. 2016). On the contrary, in unplanted soil other members of the Alpha (Sphingomonadaceae, Sphingobium, Sphingomonas, Mycoplana, Magnetospirillum) and Beta (Ralstonia, Oxalobacteraceae, Comamonadaceae, Thiobacillus) subdivisions were favoured, as well as Actinobacteria (Iamia, Geodermatophilaceae, Georgenia, and Micrococcaceae). After 16 and 22 days of root development, when no further PAH dissipation was observed, the transcriptional level of the PAH-dioxygenase gene from Gram-negative and Grampositive bacteria decreased or remained constant over time in both planted and unplanted soils. At these time points, root development seemed to mainly influence the structure of the bacterial community. The proportion of many OTUs indeed differed between the planted and unplanted soils, but organic pollutant degradation no longer did.

\section{Conclusion}

Our results suggest that the dissipation of spiked PAHs is very fast in the soil when these pollutants represent the main available carbon sources for microbial communities and PAHdegrading bacteria are present. The presence of plants, which release root exudates, could favour microbial degradation by co-metabolism and increase the PAH degradation yield. The transcription of the PAH-dioxygenase gene was higher in the presence of plants than in unplanted soil, and transcription from Gram-negative bacteria (Proteobacteria) was high during the first 12 days when most of the PAHs were degraded. In the planted condition, Gram-positive PAH-degrading bacteria (Actinobacteria) were also highly active, and probably contributed to the higher level of $\mathrm{PAH}$ degradation in the rhizosphere. The characterization of the bacterial community structure and activity over time indicated different dynamics between the two conditions, with Beta- and Gamma-Proteobacteria mostly active 
in planted soil while Alpha-Proteobacteria and Actinobacteria were more active in unplanted soil.

\section{Acknowledgments:}

This study was part of the RhizOrg project funded by the Agence Nationale de la Recherche (ANR-13-JSV7-0007_01). The authors thank the GISFI (www.gisfi.fr) for soil providing, David Billet, Geraldine Kitzinger and Gilles Bessaque for technical assistance. Carbohydrate analyses were performed by Jacqueline Marchand belonging to the PTEF facility that is supported by the French national Research Agency through the laboratory of Excellence ARBRE (ANR-11-LABX-0002-01).

\section{Figure captions}

Table 1. Nitrogenous and oxygenated pPAC concentration $\left(\mathrm{mg} \cdot \mathrm{kg}^{-1}\right)$ over time (at $\mathrm{T} 0$ and 6 days) in planted (Alf) and unplanted (BS) soils (Means $\pm \mathrm{SD}, \mathrm{n}=6$ ). Letters indicate significant differences in pPAC concentrations between T0 and 6 days, and depending on presence of plant (one-way ANOVA).

Table 2. Bacterial richness (Chao1) and diversity estimators (Inverse of Simpson's index and Evenness) in unplanted soil (BS) and soil planted with alfalfa (Alf) at the beginning (T0) and after $6,12,16$ and 22 days of incubation from cDNA data (Means $\pm \mathrm{SD}, \mathrm{n}=4$ ). The plant effect was tested (from 6 to 22 days) using a two-way analysis of variance (ANOVA) followed by Newman-Keuls multiple comparison test (letters represents groups with significant different values $(\mathrm{p}<0.05)$ ). One-way ANOVA was used to test time effect (from T0 to 22 days), separately for each condition.

Figure 1. Experimental devices and sampling points. (A) The device was composed of a mini-rhizotron (in orange) fitting in a corresponding rhizotron (in black). According to the sampling map (in white) at the depth $3 \mathrm{~cm}$, six samples (in green) were collected, 3 samples (in gray) were used for soil humidity measurements, and 4 supplemental samples collected between green locations allowed quantification of dissolved organic carbon (DOC). (B) Pictures of alfalfa rhizotron devices after $6,12,16$ and 22 days of plant growth. 
Figure 2. Soil and root colonization parameters over time. (A) Dry root biomass and length, (B) sugar content, (C) dissolved organic carbon (DOC)and (D) $\mathrm{pH}$ after 6, 12, 16 and 22 days in alfalfa planted (green) and unplanted (brown) soils. Means ( $\mathrm{n}=6$ for root biomass and length, and $\mathrm{n}=4$ for $\mathrm{pH}$ and $\mathrm{DOC})$ and standard errors. Letters indicate significant $(\mathrm{p}<0.05)$ combined effect of time and presence of plant evaluated by using two-way ANOVA followed by Neuman-Keuls multiple comparison test.

Figure 3. PAH concentration (sum of $13 \mathrm{PAH}$, i.e. the 16 US-EPA PAHs, except naphthalene, acenaphthylene and acenaphthene) after 6, 12, 16 and 22 days in planted (green) and unplanted (brown) soils. Box plots show data variability and means (black cross), $n=24$ (for T0 samples) and $n=6$ (from 6 to 22 day samples). Dashed line indicate mean of PAH concentration in the NM soil before spiking. Black asterisks indicate significant differences between planted and unplanted soil (Student t test, $\mathrm{p}<0.05)$ and letters indicate significant differences depending on time (one-way ANOVA).

Figure 4. Abundance values of genes (A) and transcripts (B) and ratio of transcripts relative to their corresponding genes $(\mathrm{C})$ for fungal $18 \mathrm{~S}$ rRNA, bacterial $16 \mathrm{~S}$ rRNA and PAHdegrading bacterial communities after 6, 12, 16 and 22 days in alfalfa planted (green) and unplanted (brown) soils. Values are means and standard deviations of 3 replicates (T0) and 6 replicates for 6 to 22 days. The effect of time was evaluated for each condition (planted, unplanted) by using one-way ANOVA $(\mathrm{p}<0.05)$ and presence of plant was evaluated between 6 and 22 days by using two-way ANOVA $(\mathrm{p}<0.05)$ followed by Neuman Keuls multiple comparison test. In $\mathrm{A}$ and $\mathrm{B}$, different letters indicate significant changes in microbial community abundance depending on time for each condition, black asterisks indicate plant effect. In $\mathrm{C}$, letters indicate cross effect of plant and time on the ratio of transcript relative to gene copies.

Figure 5. Relative proportion (mean, $n=4)$ of dominant active bacterial phyla $(\geq 1 \%$ in at least one sample) in alfalfa planted (Alf) and unplanted soil (BS) at 0, 6, 12, 16 and 22 days of incubation. The twelve significant phyla were identified by a Tukey Kramer ANOVA with a Benjamini Hochberg correction of $\mathrm{p}$-value $(\mathrm{q}<0.05$, and effect size $>0.26)$.

Figure 6. Ratio of the $16 \mathrm{~S}$ rRNA relative to $16 \mathrm{~S}$ rDNA for OTU $(\geq 10$ sequences in one sample) significantly discriminating plant effect, after 6 and 12 days of incubation. Both 
conditions were compared using Student t-tests with Benjamini-Hochberg correction of pvalue. Asterisks denote degree of significance (green and brown for higher ratio with alfalfa and unplanted soils, respectively; $\left.{ }^{*} \mathrm{q}<0.05 ; * * \mathrm{q}<0.01 ; * * * \mathrm{q}<0.001\right)$. OTUs were affiliated at $97 \%$ of similarities to the deeper taxonomic level, leading to affiliations at different levels.

Figure 7. Canonical correspondence analysis (CCA) ordination including abiotique (A) and (B) biotique variables. (A) environmental variables(in red) (DOC, sugar and organic acid contents, $\mathrm{pH}$, percentage of $18 \mathrm{~S}$ rRNA, PAH-RHD $\alpha$ GN and GPgenes and transcripts relative to $16 \mathrm{~S}$ rRNA), root biomass (RootB) and length (RootL), sum of 13 PAH concentrations, 2-3ring PAHs (fluorene, phenanthrene, anthracene), 4-ring PAHs (fluoranthene, pyrene, benzo(a)anthracene, chryzene), 5-6-ring PAHs (benzo(b)fluoranthene, benzo(k)fluoranthene, benzo(a)pyrene, dibenzo(a,h)anthracene, benzo(g,h,i)perylene, indeno(1,2,3-cd)pyrene), and (B) the relative abundance of dominant active bacterial OTUs ( $\geq 1 \%$ in at least one sample, taxonomic affiliation at $97 \%$ of similarities to the deeper taxonomic level, leading to affiliations at different levels) (in black) were used to discriminate the 24 samples (4 replicates for each sampling time corresponding to $0,6,12,16$ and 22 days) collected for alfalfa planted (green) and unplanted (brown) rhizotrons. A Monte Carlo permutation test (1000 permutations) was performed and showed a significant $(p<0.0001)$ effect of environmental variables on the relative abundance of dominant OTUs. Un. Coma.: Un. Comamonadaceae; Un. Pseudo.: Un. Pseudomonadaceae ; Un.Sphingo.: Un. Sphingomonadaceae; Un. Geo.: Un. Geodermatophilaceae; Un. Meth.:Un. Methylobacteriaceae; Phen.: Phenylobacterium ;Phaeos. Fulvum: PhaeospirillumFulvum; Un. Xantho.: Un. Xanthomonadaceae ; Un. Oxalo.: Un. Oxalobacteraceae.

\section{Supplemental data}

Table S1. PAH concentration (mg. $\left.\mathrm{L}^{-1}\right)$ in the organic extract used to spike NM soil. Values are means $(\mathrm{n}=3)$ and standard errors.

Table S2. Pearson's correlation matrix between soil properties and the percentage of PAHdioxygenase transcripts and genes. Values in bold correspond to significant correlation between variables $(\mathrm{p}<0.05)$.

Figure S1. Bioavailable (A) and total (B) PAH concentration in NM soil before (grey) and after (blue) spiking. Black asteriks indicates significant differences between both conditions 
661

662

663

664

665

666

667

668

669

670

671

672

673

674

675

676

677

678

679

680

681

682

683

684

685

686

687

688

689

690

(Student $\mathrm{t}$ test, $\mathrm{p}<0,05$ ). Values are means and standard deviation of 12 and 48 samples (total fraction) and 8 and 6 samples (bioavailable fraction), before and after spiking respectively.

Figure S2. Total PAH concentration of 13 individual compounds (the 16 US-EPA PAHs except naphthalene, acenaphthylene and acenaphthene) after 6, 12, 16 and 22 days in alfalfa planted (green) and unplanted (brown) soils. Values are means and standard deviations of 24 replicates ( 0 day) and 6 replicates from 6 to 22 days. The effect of time was evaluated for each condition (planted, unplanted) independently by using one-way ANOVA $(p<0.05)$ and effect of presence of plant was evaluated between T1 and T4 by using two-way ANOVA $(p<0.05)$ followed by Neuman Keuls multiple comparison test. Different letters indicate significant differences in PAH concentration depending on time for each condition, black asterisks indicate plant effect.

Figure S3. Evolution over time of the relative proportion of dominant OTUs $(\geq 1 \%$ in at least one sample), in alfalfa planted and unplanted soil, reported to the transcript 16S rRNA copy number based on cDNA analysis. Forty-seven significant OTUs were identified by a Tukey Kramer ANOVA with a Benjamini Hochberg correction of $\mathrm{p}$-value $(\mathrm{q}<0.05$, and effect size $>0.26$ ) and non-significant OTUs correspond to population presenting constant relative proportion over time. Asterisks denote OTUs with significant differences in relative abundance over time specifically in planted (green) or in unplanted soil (brown). OTUs were affiliated at the most precise level.

Figure S4. Ratio of the 16S rRNA relative to $16 \mathrm{~S}$ rDNA for OTU (with at least 10 sequences in one sample) significantly discriminating plant effect, after 16 and 22 days of incubation. Both conditions were compared using Student t-tests with Benjamini-Hochberg correction of p-value. Asterisks denote degree of significance (green and brown for higher ratio with alfalfa planted and unplanted soils, respectively; $\left.{ }^{*} \mathrm{q}<0.05 ; * * \mathrm{q}<0.01 ; * * * \mathrm{q}<0.001\right)$.

\section{References}

Allard A-S, Remberger M, Neilson AH (2000) The negative impact of aging on the loss of PAH components in a creosote-contaminated soil. Int Biodeterior Biodegradation 46:4349 . doi: 10.1016/S0964-8305(00)00050-0 
Ambrosoli R, Petruzzelli L, Minati JL, Marsan FA (2005) Anaerobic PAH degradation in soil by a mixed bacterial consortium under denitrifying conditions. Chemosphere 60:12311236 . doi: 10.1016/j.chemosphere.2005.02.030

Baudoin E, Benizri E, Guckert A (2002) Impact of growth stage on the bacterial community structure along maize roots, as determined by metabolic and genetic fingerprinting. Appl Soil Ecol 19:135-145 . doi: 10.1016/S0929-1393(01)00185-8

Bell TH, El-Din Hassan S, Lauron-Moreau A, et al (2014) Linkage between bacterial and fungal rhizosphere communities in hydrocarbon-contaminated soils is related to plant phylogeny. Isme J 8:331-343 . doi: 10.1038/ismej.2013.149

Benhabib K, Faure P, Sardin M, Simonnot MO (2010) Characteristics of a solid coal tar sampled from a contaminated soil and of the organics transferred into water. Fuel 89:352-359 . doi: 10.1016/j.fuel.2009.06.009

Bevivino A, Dalmastri C (2017) Composition and Function of Microbial Communities in Soil Ecosystems. In: Soil Biological Communities and Ecosystem Resilience. pp 79-81

Biache C, Ouali S, Cébron A, et al (2017) Bioremediation of PAH-contamined soils: Consequences on formation and degradation of polar-polycyclic aromatic compounds and microbial community abundance. J Hazard Mater 329:1-10 . doi: 10.1016/j.jhazmat.2017.01.026

Bogan BW, Sullivan WR (2003) Physicochemical soil parameters affecting sequestration and mycobacterial biodegradation of polycyclic aromatic hydrocarbons in soil. Chemosphere 52:1717-1726 . doi: 10.1016/S0045-6535(03)00455-7

Bourceret A, Cébron A, Tisserant E, et al (2016) The Bacterial and Fungal Diversity of an Aged PAH- and Heavy Metal-Contaminated Soil is Affected by Plant Cover and Edaphic Parameters. Microb Ecol 1-14 . doi: 10.1007/s00248-015-0682-8

Bourceret A, Leyval C, De Fouquet C, Cébron A (2015) Mapping the centimeter-scale spatial variability of PAHs and microbial populations in the rhizosphere of two plants. PLoS One 10:

Bourceret A, Leyval C, Thomas F, Cébron A (2017) Rhizosphere effect is stronger than PAH concentration on shaping spatial bacterial assemblages along centimetre-scale depth 
Caporaso JG, Kuczynski J, Stombaugh J, et al (2010) QIIME allows analysis of highthroughput community sequencing data. Nat Methods 7:335-336 . doi: 10.1038/nmeth.f.303

Castro-Silva C, Ruíz-Valdiviezo VM, Valenzuela-Encinas C, et al (2013) The bacterial community structure in an alkaline saline soil spiked with anthracene. Electron $\mathrm{J}$ Biotechnol 16:1-20 . doi: 10.2225/vol16-issue5-fulltext-14

Cébron A, Beguiristain T, Faure P, et al (2009) Influence of vegetation on the in situ bacterial community and polycyclic aromatic hydrocarbon (PAH) degraders in aged PAHcontaminated or thermal-desorption-treated soil. Appl Environ Microbiol 75:6322-6330 . doi: 10.1128/AEM.02862-08

Cébron A, Cortet J, Criquet S, et al (2011) Biological functioning of PAH-polluted and thermal desorption-treated soils assessed by fauna and microbial bioindicators. Res Microbiol 162:897-907 . doi: 10.1016/j.resmic.2011.02.011

Cébron A, Faure P, Lorgeoux C, et al (2013) Experimental increase in availability of a PAH complex organic contamination from an aged contaminated soil: Consequences on biodegradation. Environ Pollut 177:98-105 . doi: 10.1016/j.envpol.2013.01.043

Cébron A, Norini MP, Beguiristain T, Leyval C (2008) Real-Time PCR quantification of PAH-ring hydroxylating dioxygenase (PAH-RHD $\alpha$ ) genes from Gram positive and Gram negative bacteria in soil and sediment samples. J Microbiol Methods 73:148-159 . doi: 10.1016/j.mimet.2008.01.009

Cerniglia CE, Sutherland JB (2010) Degradation of polycyclic aromatic hydrocarbons by fungi. In: (Berlin: Springer; ) (ed) Handbook of Hydrocarbon and Lipid Microbiology, Timmis K. pp 2080-2110

D’Orazio V, Ghanem A, Senesi N (2013) Phytoremediation of pyrene contaminated soils by different plant species. Clean - Soil, Air, Water 41:377-382 . doi: 10.1002/clen.201100653

de Menezes A, Clipson N, Doyle E (2012) Comparative metatranscriptomics reveals widespread community responses during phenanthrene degradation in soil. Environ 
Microbiol 14:2577-2588 . doi: 10.1111/j.1462-2920.2012.02781.x

750

751

752

753

754

755

756

757

758

759

760

761

762

763

764

765

766

767

768

769

770

771

772

773

774

775

776

777

Felske A, Akkermans ADL, De Vos WM (1998) Quantification of 16S rRNAs in complex bacterial communities by multiple competitive reverse transcription-PCR in temperature gradient gel electrophoresis fingerprints. Appl Environ Microbiol 64:4581-4587

Fernández-Luqueño F, Valenzuela-Encinas C, Marsch R, et al (2011) Microbial communities to mitigate contamination of PAHs in soil—possibilities and challenges: a review. Environ Sci Pollut Res 18:12-30

Gartler J, Wimmer B, Soja G, Reichenauer TG (2014) Effects of Rapeseed Oil on the Rhizodegradation of Polyaromatic Hydrocarbons in Contaminated Soil. Int J Phytoremediation 16:671-683 . doi: 10.1080/15226514.2013.856841

Ghosal D, Ghosh S, Dutta TK, Ahn Y (2016) Current state of knowledge in microbial degradation of polycyclic aromatic hydrocarbons (PAHs): A review. Front Microbiol 7: . doi: 10.3389/fmicb.2016.01369

Gupta S, Pathak B, Fulekar MH (2015) Molecular approaches for biodegradation of polycyclic aromatic hydrocarbon compounds: a review. Rev Environ Sci Biotechnol 14:241-269 . doi: 10.1007/s11157-014-9353-3

Haichar F el Z, Santaella C, Heulin T, Achouak W (2014) Root exudates mediated interactions belowground. Soil Biol Biochem 77:69-80 . doi: 10.1016/j.soilbio.2014.06.017

Haichar F el Z, Marol C, Berge O, et al (2008) Plant host habitat and root exudates shape soil bacterial community structure. ISME J 2:1221-1230 . doi: 10.1038/ismej.2008.80

Hannula SE, de Boer W, van Veen JA (2010) In situ dynamics of soil fungal communities under different genotypes of potato, including a genetically modified cultivar. Soil Biol Biochem 42:2211-2223 . doi: 10.1016/j.soilbio.2010.08.020

Hanser O, Biache C, Boulangé M, et al (2015) Evolution of dissolved organic matter during abiotic oxidation of coal tar-comparison with contaminated soils under natural attenuation. Environ Sci Pollut Res 22:1431-1443

Haritash AK, Kaushik CP (2009) Biodegradation aspects of Polycyclic Aromatic Hydrocarbons (PAHs): A review. J Hazard Mater 169:1-15 . doi: 
Hinsinger P, Gobran GR, Gregory PJ, Wenzel WW (2005) Rhizosphere geometry and heterogeneity arising from root-mediated physical and chemical processes. New Phytol 168:293-303 . doi: 10.1111/j.1469-8137.2005.01512.x

Joner EJ, Corgié SC, Amellal N, Leyval C (2002) Nutritional constraints to degradation of polycyclic aromatic hydrocarbons in a simulated rhizosphere. Soil Biol Biochem 34:859-864 . doi: 10.1016/S0038-0717(02)00018-4

Kanaly R, Harayama S (2000) Biodegradation of High-Molecular-Weight Polycyclic Aromatic Hydrocarbons by Bacteria MINIREVIEW Biodegradation of High-MolecularWeight Polycyclic Aromatic Hydrocarbons by Bacteria. J Bacteriol 182:2059-2067 . doi: 10.1128/JB.182.8.2059-2067.2000.Updated

Kawasaki A, Warren CR, Kertesz MA (2015) Specific influence of white clover on the rhizosphere microbial community in response to polycyclic aromatic hydrocarbon (PAH) contamination. Plant Soil 1-15

Kawasaki A, Watson E, Kertesz M (2012) Indirect effects of polycyclic aromatic hydrocarbon contamination on microbial communities in legume and grass rhizospheres. Plant Soil 358:169-182 . doi: 10.1007/s11104-011-1089-z

Kim S-J, Kweon O, Freeman JP, et al (2006) Molecular Cloning and Expression of Genes Encoding a Novel Dioxygenase Involved in Low- and High-Molecular-Weight Polycyclic Aromatic Hydrocarbon Degradation in Mycobacterium vanbaalenii PYR-1. Appl Environ Microbiol 72:1045-1054

Kirk JL, Klironomos JN, Lee H, Trevors JT (2005) The effects of perennial ryegrass and alfalfa on microbial abundance and diversity in petroleum contaminated soil. Environ Pollut 133:455-465 . doi: 10.1016/j.envpol.2004.06.002

Kunihiro M, Ozeki Y, Nogi Y, et al (2013) Benz[a]anthracene biotransformation and production of ring fission products by Sphingobium sp. strain KK22. Appl Environ Microbiol 79:4410-4420 . doi: 10.1128/AEM.01129-13

Leigh MB, Fletcher JS, Fu X, Schmitz FJ (2002) Root turnover: An important source of microbial substrates in rhizosphere remediation of recalcitrant contaminants. Environ Sci 
Liste H-H, Alexander M (2000) Plant-promoted pyrene degradation in soil. Chemosphere 40:7-10 . doi: 10.1016/S0045-6535(99)00216-7

Louvel B, Cébron A, Leyval C (2011) Root exudates affect phenanthrene biodegradation, bacterial community and functional gene expression in sand microcosms. Int Biodeterior Biodegrad 65:947-953 . doi: 10.1016/j.ibiod.2011.07.003

Lueders T, Wagner B, Claus P, Friedrich MW (2004) Stable isotope probing of rRNA and DNA reveals a dynamic methylotroph community and trophic interactions with fungi and protozoa in oxic rice field soil. Environ Microbiol 6:60-72 . doi: 10.1046/j.14622920.2003.00535.x

Lundstedt S, Persson Y, Öberg L (2006) Transformation of PAHs during ethanol-Fenton treatment of an aged gasworks' soil. Chemosphere 65:1288-1294

Lundstedt S, White PA, Lemieux CL, et al (2007) Sources, fate, and toxic hazards of oxygenated polycyclic aromatic hydrocarbons (PAHs) at PAH-contaminated sites. AMBIO A J Hum Environ 36:475-485

McDonald D, Price MN, Goodrich J, et al (2012) An improved Greengenes taxonomy with explicit ranks for ecological and evolutionary analyses of bacteria and archaea. ISME $\mathbf{J}$ 6:610-8 . doi: 10.1038/ismej.2011.139

Muratova AY, Turkovskaya O V., Hübner T, Kuschk P (2003) Studies of the Efficacy of Alfalfa and Reed in the Phytoremediation of Hydrocarbon-Polluted Soil. Appl Biochem Microbiol 39:599-605 . doi: 10.1023/A:1026238720268

Northcott GL, Jones KC (2001) Partitioning, extractability, and formation of nonextractable PAH residues in soil. 2. Effects on compound dissolution behavior. Environ Sci Technol $35: 1111-1117$

Parks DH, Beiko RG (2010) Identifying biologically relevant differences between metagenomic communities. Bioinformatics 26:715-721

Peng A, Liu J, Ling W, et al (2015) Diversity and distribution of 16S rRNA and phenol monooxygenase genes in the rhizosphere and endophytic bacteria isolated from PAHcontaminated sites. Sci Rep 5:12173 . doi: 10.1038/srep12173 
Reid BJ, Stokes JD, Jones KC, Semple KT (2000) Nonexhaustive cyclodextrin-based extraction technique for the evaluation of PAH bioavailability. Environ Sci Technol 34:3174-3179 . doi: 10.1021/es990946c

Rentz JA, Alvarez PJJ, Schnoor JL (2005) Benzo[a]pyrene co-metabolism in the presence of plant root extracts and exudates: Implications for phytoremediation. Environ Pollut 136:477-484 . doi: 10.1016/j.envpol.2004.12.034

Rollin C, Quiot F, DENYS S, BUREAU J (2005) Hydrocarbures Aromatiques Polycycliques. Guide méthodologique. Acquisition des données d'entrée des modèles analytiques ou numériques de transferts dans les sols et les eaux souterraines. INERIS-DRC66244/DESP-R01

Roy M, Khara P, Basu S, Dutta TK (2013) Catabolic Versatility of Sphingobium sp. Strain PNB Capable of Degrading Structurally Diverse Aromatic Compounds. J Bioremediation Biodegrad 4:1-6 . doi: 10.4172/2155-6199.1000173

Rumberger A, Marschner P (2003) 2-Phenylethylisothiocyanate concentration and microbial community composition in the rhizosphere of canola. Soil Biol Biochem 35:445-452 . doi: 10.1016/S0038-0717(02)00296-1

Sawulski P, Clipson N, Doyle E (2014) Effects of polycyclic aromatic hydrocarbons on microbial community structure and $\mathrm{PAH}$ ring hydroxylating dioxygenase gene abundance in soil. Biodegradation 25:835-847 . doi: 10.1007/s10532-014-9703-4

Siciliano SD, Germida JJ, Banks K, Greer CW (2003) Changes in Microbial Community Composition and Function during a Polyaromatic Hydrocarbon Phytoremediation Field Trial. Appl Environ Microbiol 69:483-489

Storey S, Ashaari MM, Mccabe G, et al (2014) Microbial community structure during fluoranthene degradation in the presence of plants. J Appl Microbiol 117:74-84 . doi: $10.1111 /$ jam. 12518

Tauler M, Vila J, Nieto JM, Grifoll M (2015) Key high molecular weight PAH-degrading bacteria in a soil consortium enriched using a sand-in-liquid microcosm system. Appl Microbiol Biotechnol 1-16

Tejeda-Agredano MC, Gallego S, Vila J, et al (2013) Influence of the sunflower rhizosphere 
on the biodegradation of PAHs in soil. Soil Biol Biochem 57:830-840 . doi: 10.1016/j.soilbio.2012.08.008

Thion C, Cébron A, Beguiristain T, Leyval C (2013) Inoculation of PAH-degrading strains of Fusarium solani and Arthrobacter oxydans in rhizospheric sand and soil microcosms: microbial interactions and PAH dissipation. Biodegradation 24:569-581 . doi: $10.1007 / \mathrm{s} 10532-013-9628-3$

Thion C, Cébron A, Beguiristain T, Leyval C (2012) Long-term in situ dynamics of the fungal communities in a multi-contaminated soil are mainly driven by plants. FEMS Microbiol Ecol 82:169-181 . doi: 10.1111/j.1574-6941.2012.01414.x

Thomas F, Cébron A (2016) Short-term rhizosphere effect on available carbon sources, phenanthrene degradation, and active microbiome in an aged-contaminated industrial soil. Front Microbiol 7:1-15 . doi: 10.3389/fmicb.2016.00092

Thomas F, Lorgeoux C, Faure P, et al (2016) Isolation and substrate screening of polycyclic aromatic hydrocarbon degrading bacteria from soil with long history of contamination. Int Biodeterior Biodegradation 107:1-9

Trapp S, Karlson U (2001) Aspects of phytoremediation of organic pollutants. J Soils Sediments 1:37-43 . doi: 10.1065/jss2001.04.007

Turner S, Pryer KM, Miao VP, Palmer JD (1999) Investigating deep phylogenetic relationships among cyanobacteria and plastids by small subunit rRNA sequence analysis1. J Eukaryot Microbiol 46:327-338

van Herwijnen R, Wattiau P, Bastiaens L, et al. (2003) Elucidationn of the metabolic pathway of fluorene and cometabolicc pathways of phenanthrene, fluoranthene, anthracenee and dibenzothiophene by Sphingomonas sp . Res Microbiol 154:199-206

Vrchotová B, Lovecká P, Dražková M, et al (2013) Influence of root exudates on the bacterial degradation of chlorobenzoic acids. Sci World J 2013: . doi: 10.1155/2013/872026

Walker TS, Bais HP, Grotewold E, Vivanco JM (2003) Root exudation and rhizosphere biology. Plant Physiol 132:44-51

Wang Q, Garrity GM, Tiedje JM, Cole JR (2007) Naïve Bayesian Classifier for Rapid Assignment of rRNA Sequences into the New Bacterial Taxonomy. Appl Environ 
895

896

897

898

899

900

901

902

903

904

905

906

907

Yang C-H, Crowley DE (2000) Rhizosphere Microbial Community Structure in Relation to Root Location and Plant Iron Nutritional Status. Appl Environ Microbiol 66:345-351 . doi: 10.1128/AEM.66.1.345-351.2000

Yergeau E, Sanschagrin S, Maynard C, et al (2014) Microbial expression profiles in the rhizosphere of willows depend on soil contamination. ISME J 8:344-58 . doi: 10.1038/ismej.2013.163

Zhang Z, Zhao X, Liang Y, et al (2013) Microbial functional genes reveal selection of microbial community by PAHs in polluted soils. Environ Chem Lett 11:11-17 . doi: 10.1007/s10311-012-0370-6

Zhou W, Yang J, Lou L, Zhu L (2011) Solubilization properties of polycyclic aromatic hydrocarbons by saponin, a plant-derived biosurfactant. Environ Pollut 159:1198-1204 
Figure 1.

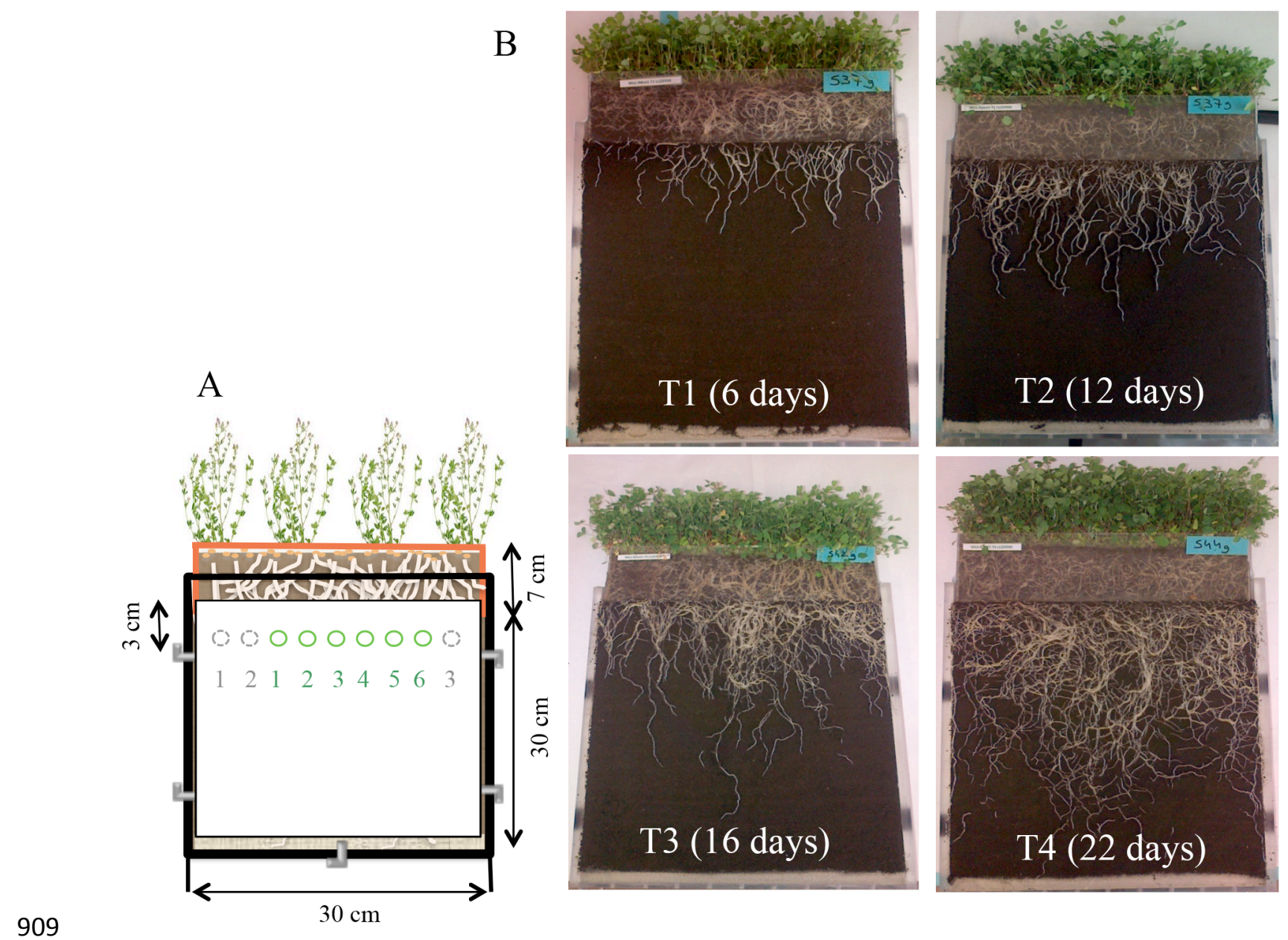


Figure 2.
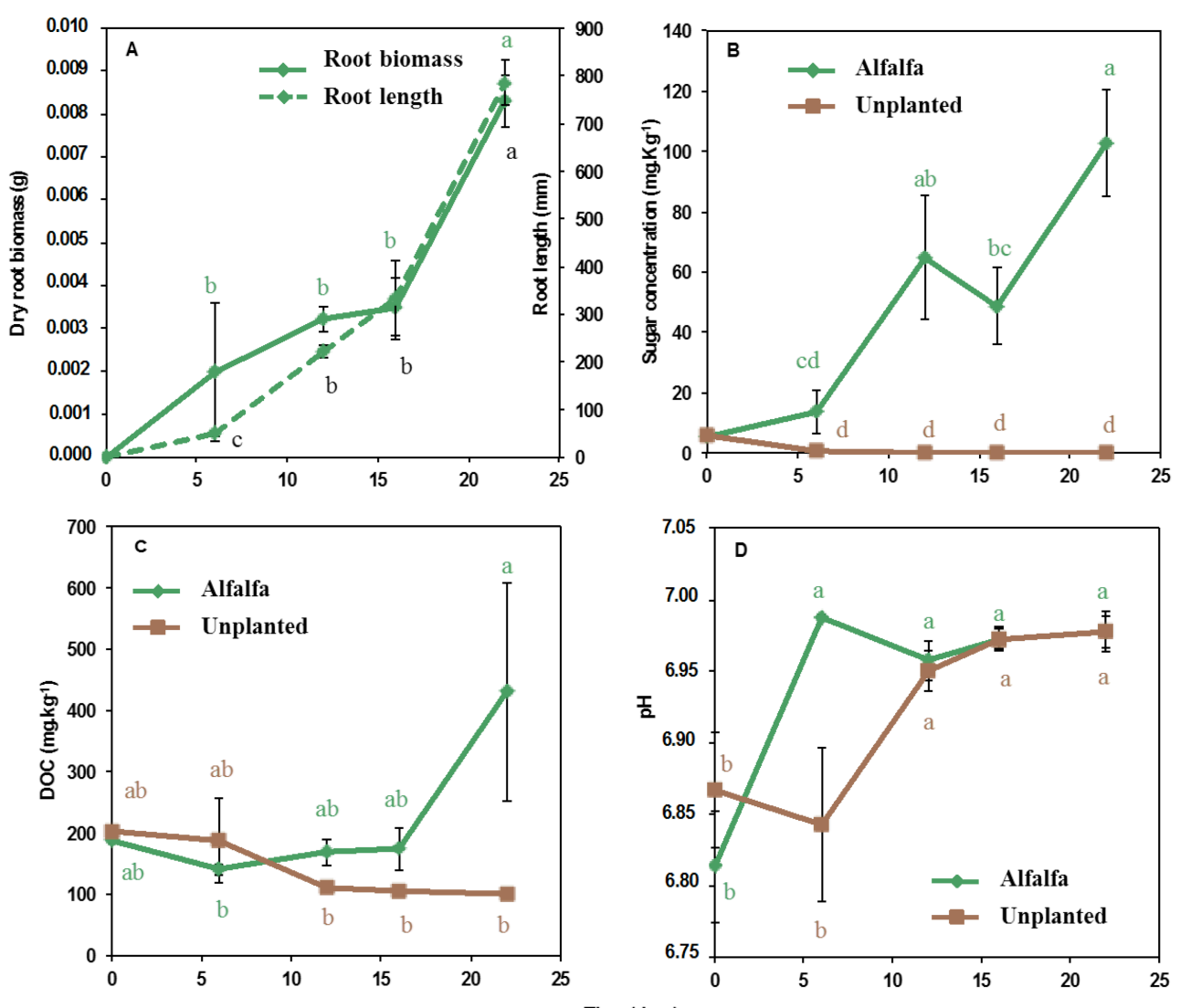
914 Figure 3.

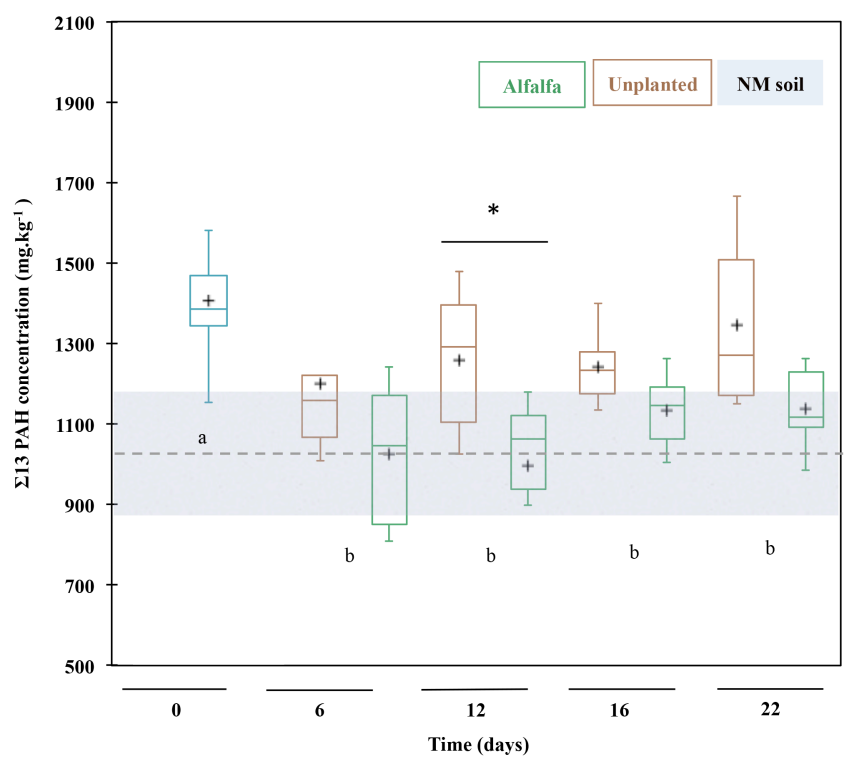


Figure 4.
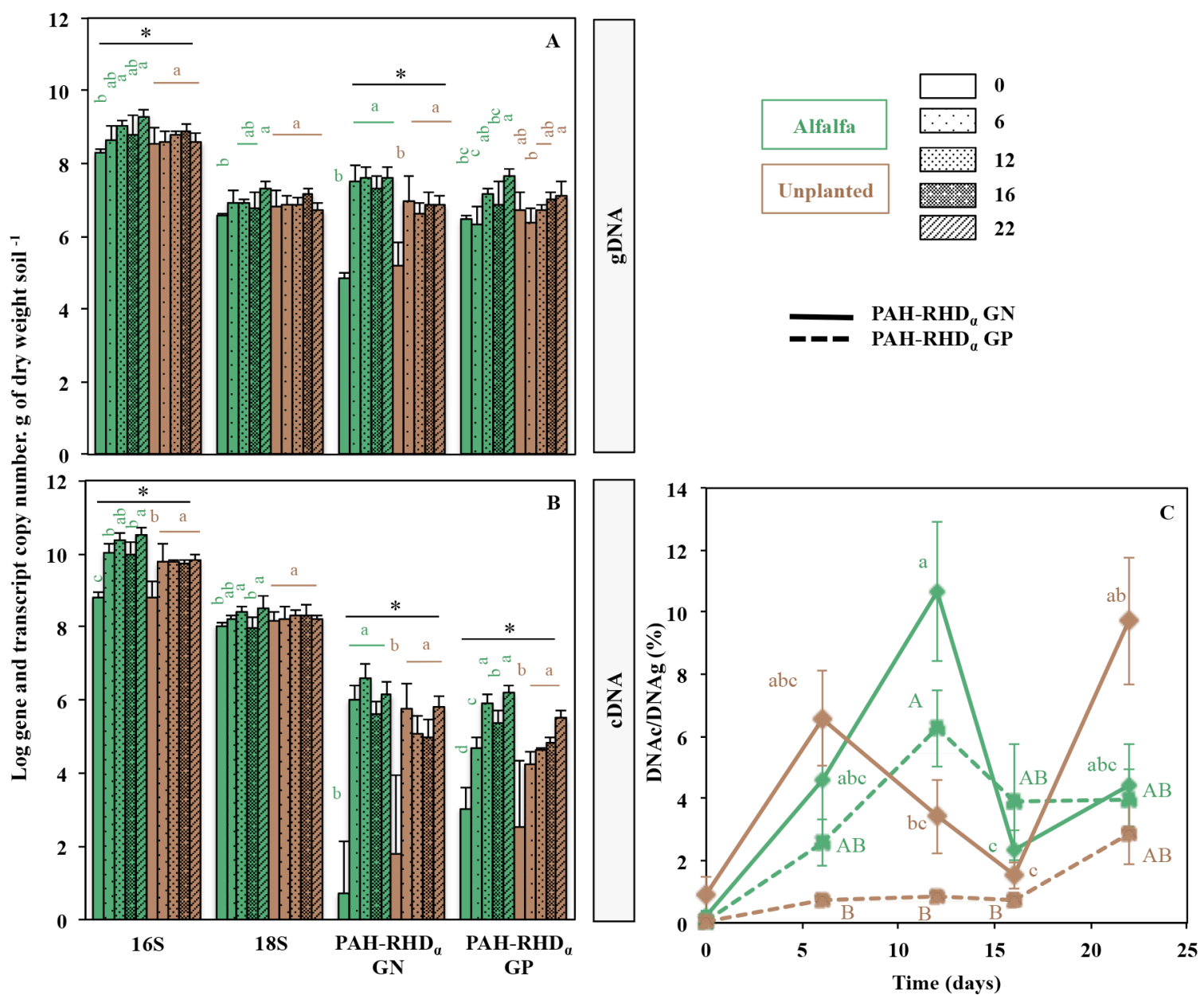
Figure 5.

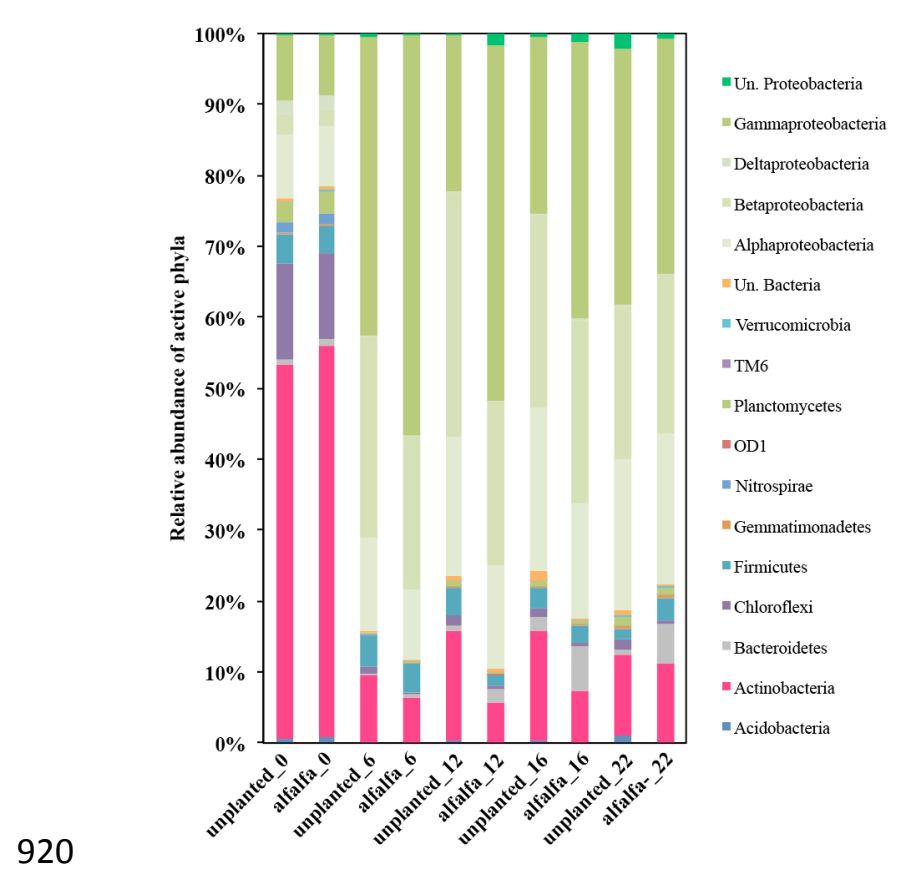

921 


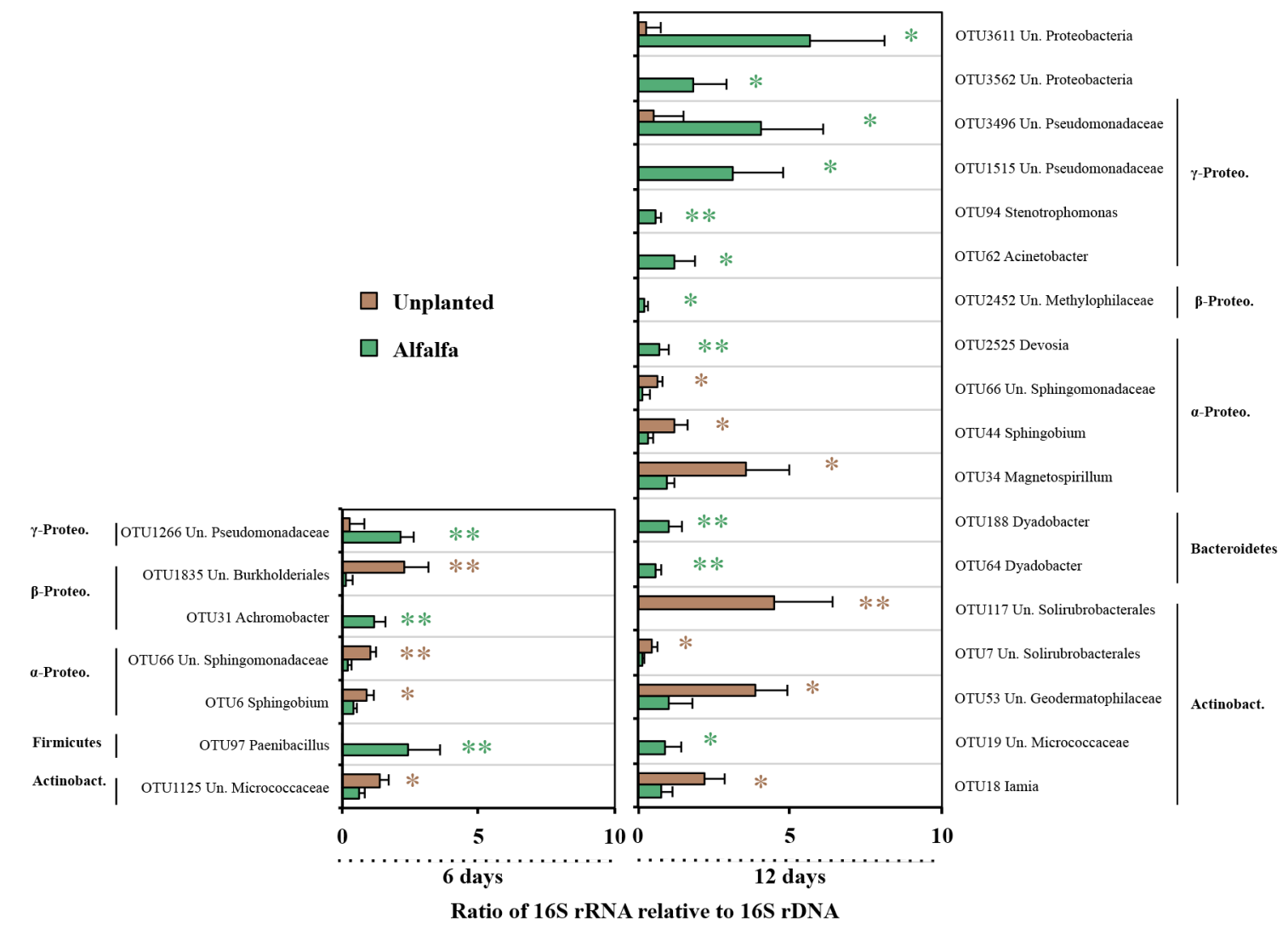



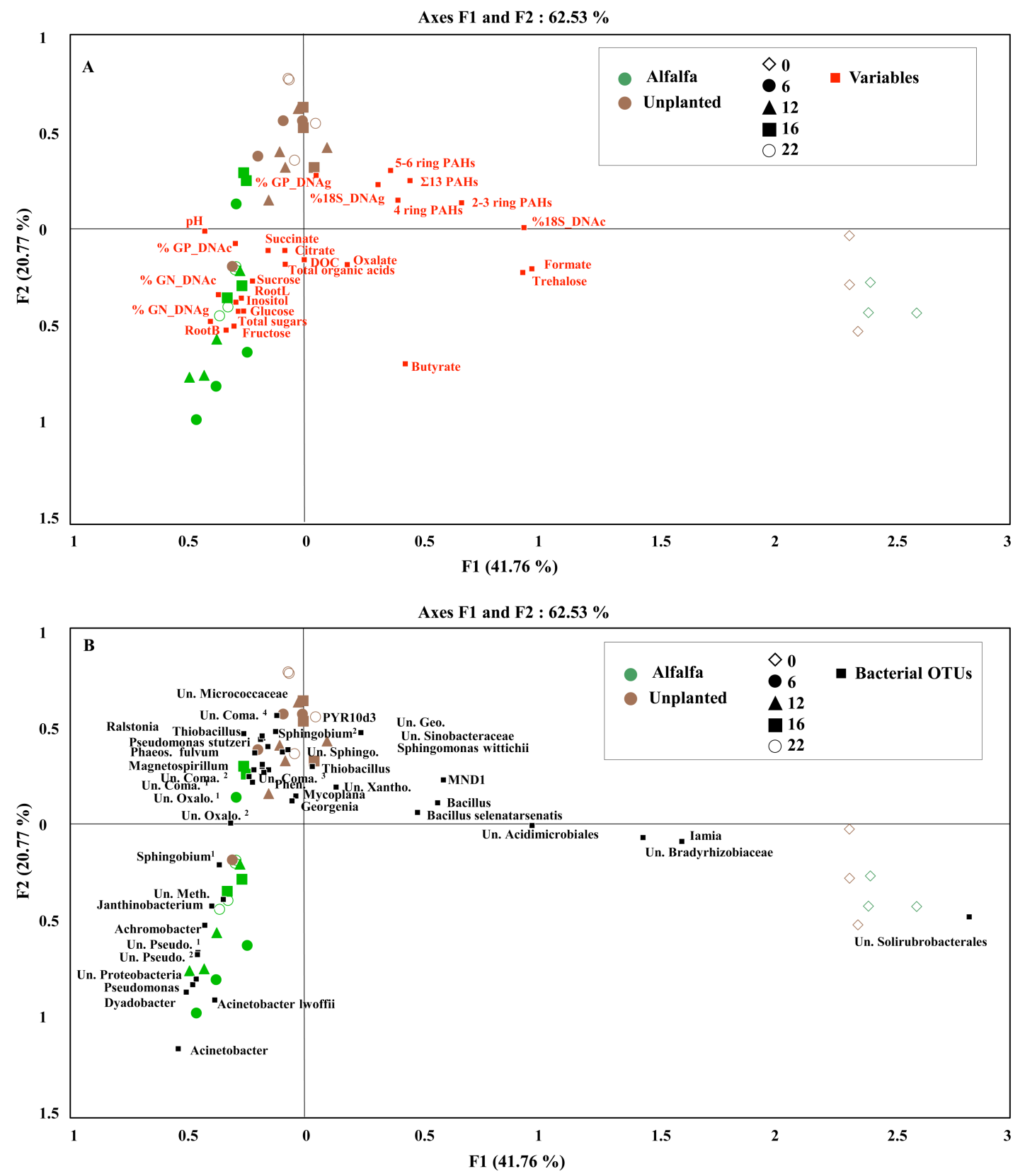
929 Figure S1.

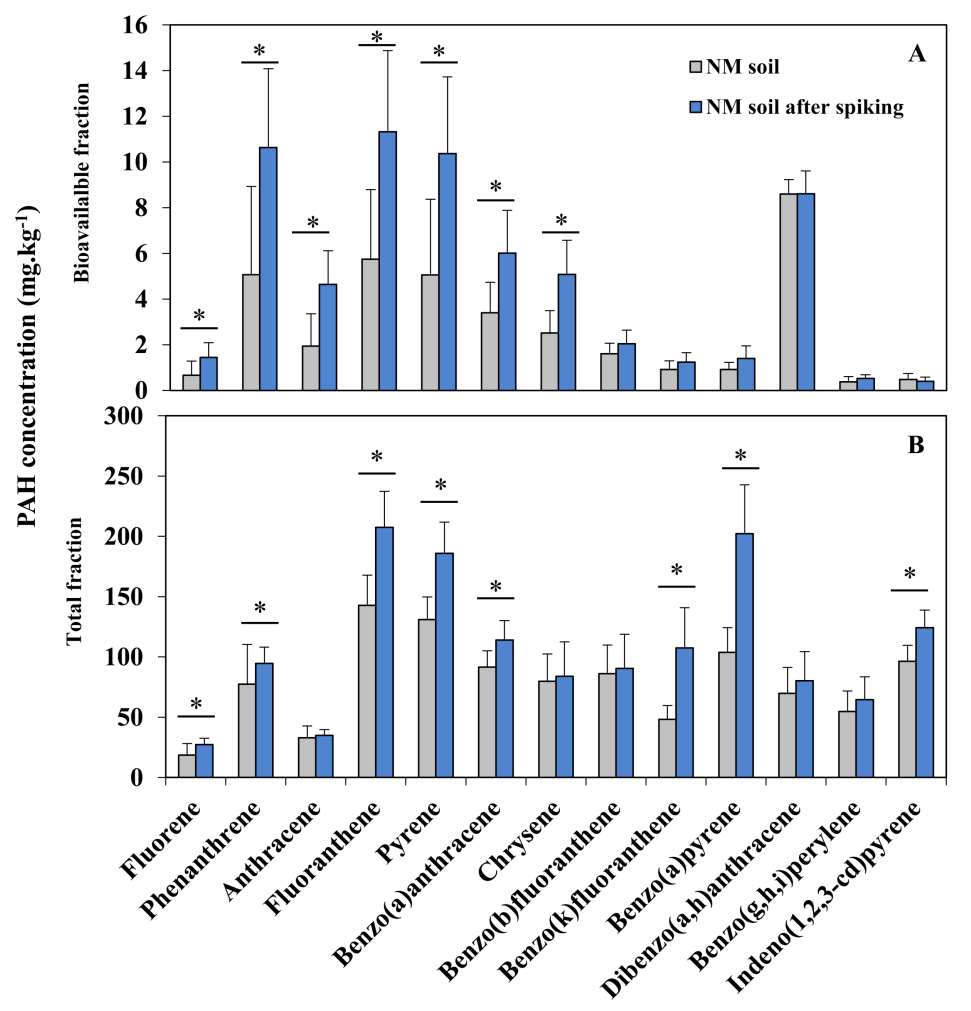

930

931 Figure S2.

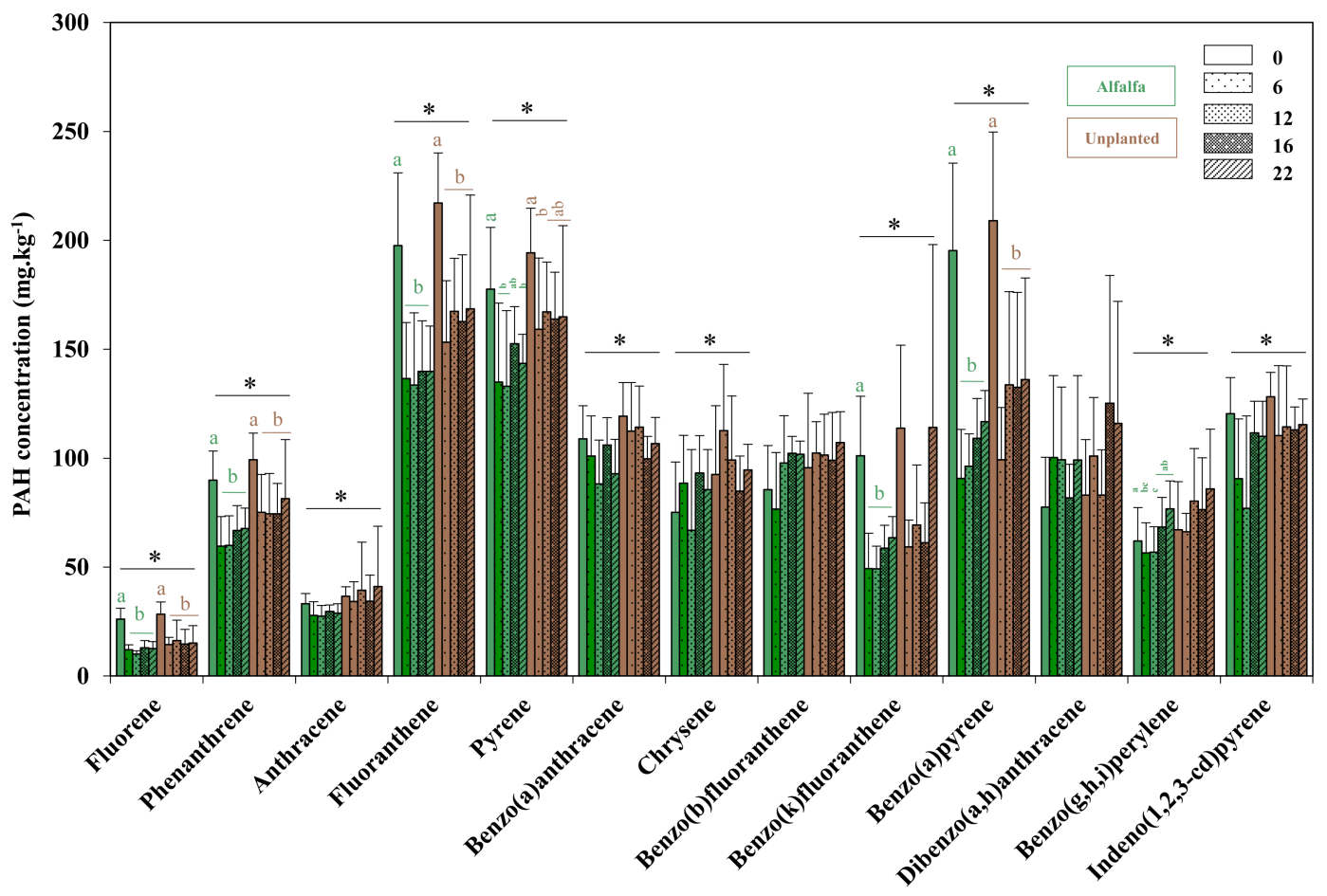




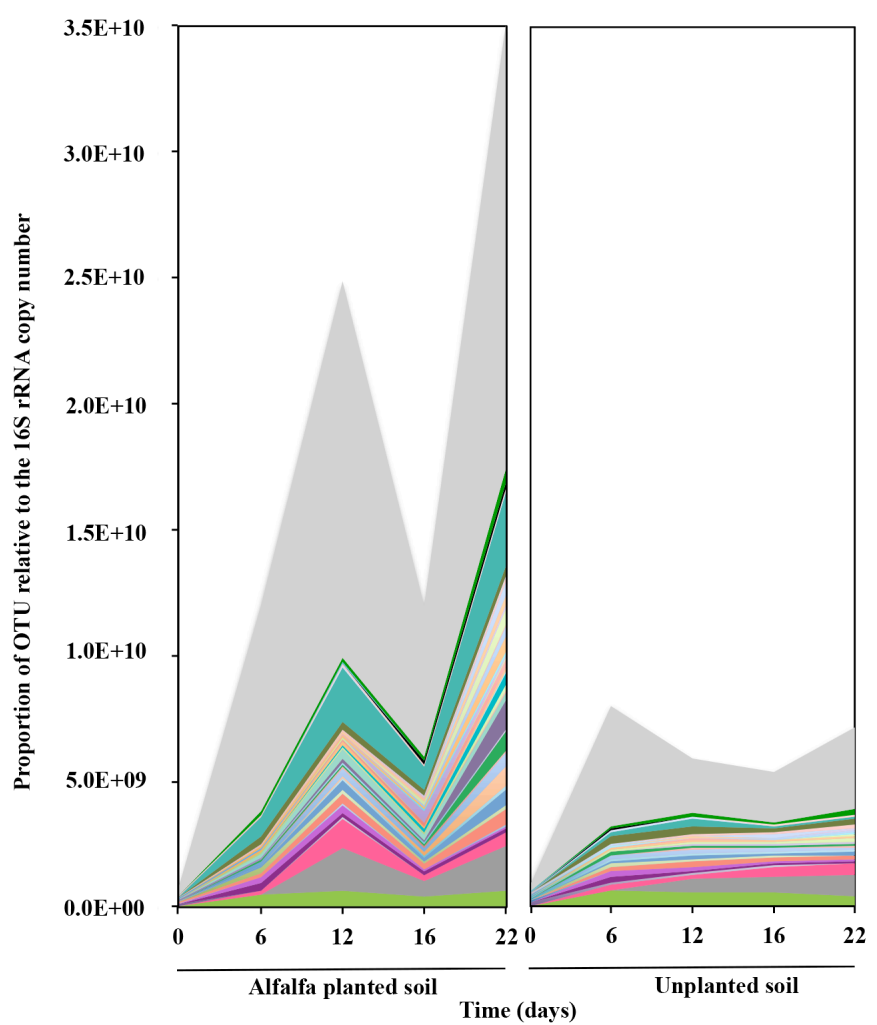

Non significant OTUs

OTU3515: Sphingomonadaceae *

- OTU3203: Sphingomonadaceae

OTU2314: Xanthomonadaceae

OTU2306: Bradyrhizobiaceae

OTU2227: Janthinobacterium

OTU1798: Nocardioidace

OTU1723: Syntrophaceae

OTU1443: Comamonadaceae $*$

OTU1125: Micrococcaceae

OTU949: Devosia *

OTU331: Nitrospira

OTU68: Gammaproteobacteria *

OTU61: Acidimicrobiales

OTU57: Cellvibrio *

OTU55: Paenibacillus

OTU54: Proteobacteria *

OTU51: Flavobacterium *

OTU46: Nocardioidaceae

-OTU38: Piscirickettsiacea

OTU37: Sinobacteraceae

- OTU36: Gaiellales

-OTU35: Flavobacterium *

OTU34: Magnetospirillum

OTU32: Acidimicrobiales

-

-OTU2. Devosia *

OTU28. Iamia microbium

- OTU25: Coma

24: MND1 *

-OTU20: Phenylobacteriu

OTU19: Micrococcaceae *

OTU18: Iamia

OTU15: Mycomonadaceae

OTU14: Acidimicro

OTU11: Gitt-GS-136

OTU9: Oxalobacteraceae *

OTU8: Bacillus



OTU. PYR 10d3

-OTU0: Thiobacillus

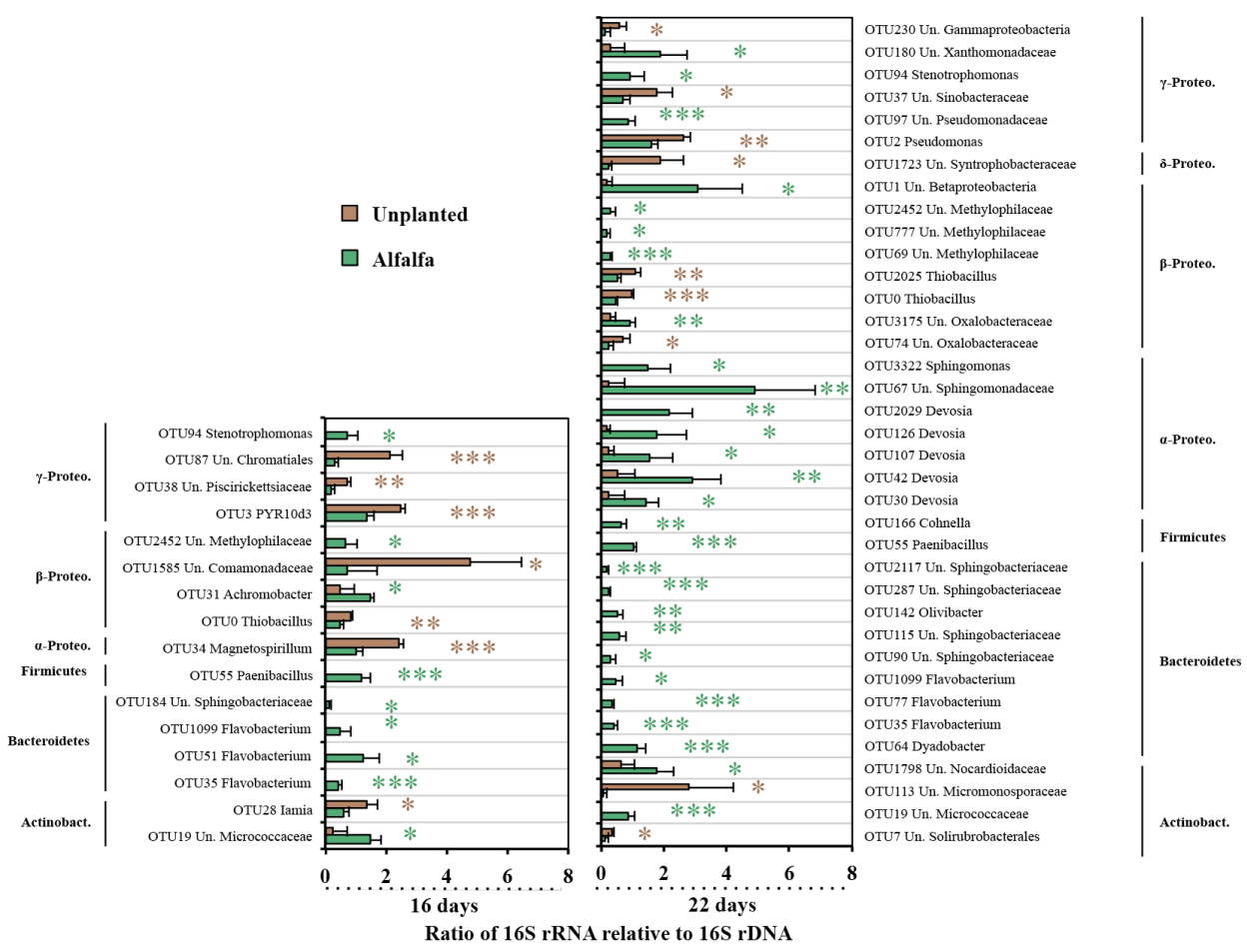


939 Table S2. PAH concentration $\left(\mathrm{mg} \cdot \mathrm{L}^{-1}\right)$ in the organic extract used to spike NM soil. Values are means $(\mathrm{n}=3)$ and standard errors.

940

941

942

PAHs concentration $(\mathrm{mg} / \mathrm{L})$

\begin{tabular}{|c|c|c|c|c|c|c|c|c|c|c|c|c|}
\hline & & & & & Benzo(a) & & Benzo(b) & Benzo(k) & Benzo(a) & Dibenzo(a,h) & $\operatorname{Benzo}(\mathbf{g}, \mathbf{h}, \mathbf{i})$ & Indeno(1,2,3-cd) \\
\hline Fluorene & Phenanthrene & Anthracene & Fluoranthene & Pyrene & anthracene & Chrysene & fluoranthene & fluoranthene & pyrene & anthracene & perylene & pyrene \\
\hline $24.8 \pm 2.3$ & $98.7 \pm 4.2$ & $35.9 \pm 1.6$ & $221.8 \pm 16.7$ & $200.9 \pm 11.7$ & $126.3 \pm 12.2$ & $101.1 \pm 6.8$ & $115.7 \pm 10.8$ & $70.7 \pm 10.3$ & $28.2 \pm 7.6$ & $70.3 \pm 7.0$ & $77.2 \pm 7.8$ & $101.7 \pm 10.3$ \\
\hline
\end{tabular}

943

\begin{tabular}{cccccccccc}
\hline Variables & Time & $\begin{array}{c}2-3 \text { ring } \\
\text { PAH }\end{array}$ & $\begin{array}{c}4 \text { ring } \\
\text { PAH }\end{array}$ & $\begin{array}{c}5-6 \text { ring } \\
\text { PAH }\end{array}$ & $\begin{array}{c}\Sigma 13 \\
\text { PAHs }\end{array}$ & pH & DOC & \multirow{2}{*}{ RootB } & \multirow{2}{*}{ RootL } \\
\hline \%18S_DNAc & $\mathbf{- 0 . 6 4 6}$ & $\mathbf{0 . 6 8 6}$ & $\mathbf{0 . 4 5 1}$ & $\mathbf{0 . 3 6 1}$ & $\mathbf{0 . 4 7 4}$ & $\mathbf{- 0 . 6 0 3}$ & -0.028 & $\mathbf{- 0 . 3 6 0}$ & $\mathbf{- 0 . 3 3 8}$ \\
& & & & & & & & & \\
\% PAH-RHD $\alpha$ GN_DNAc & 0.106 & $\mathbf{- 0 . 4 3 4}$ & $\mathbf{- 0 . 3 9 1}$ & -0.220 & $\mathbf{- 0 . 3 3 9}$ & 0.059 & -0.094 & 0.062 & 0.010 \\
\% PAH-RHD $\alpha$ GP_DNAc & $\mathbf{0 . 7 3 3}$ & -0.204 & -0.253 & 0.137 & -0.053 & $\mathbf{0 . 4 0 9}$ & 0.154 & $\mathbf{0 . 4 5 2}$ & $\mathbf{0 . 5 3 8}$ \\
\hline \%18S_DNAg & $\mathbf{- 0 . 5 0 2}$ & 0.283 & 0.199 & 0.064 & 0.154 & $\mathbf{- 0 . 3 8 6}$ & -0.151 & $\mathbf{- 0 . 3 6 3}$ & $\mathbf{- 0 . 4 8 5}$ \\
\% PAH-RHD $\alpha$ GN_DNAg & -0.032 & $\mathbf{- 0 . 5 1 2}$ & $\mathbf{- 0 . 4 4 8}$ & $\mathbf{- 0 . 5 3 0}$ & $\mathbf{- 0 . 5 4 7}$ & 0.213 & -0.029 & $\mathbf{0 . 3 4 9}$ & 0.052 \\
& & & & & & & & & \\
\% PAH-RHD $\alpha$ GP_DNAg & $\mathbf{0 . 4 9 7}$ & 0.163 & 0.094 & $\mathbf{0 . 3 8 8}$ & 0.277 & 0.170 & 0.092 & 0.049 & 0.120 \\
\hline
\end{tabular}


Table S1. Pearson's correlation matrix between soil properties and the percentage of PAH-dioxygenase transcript and genes. Values in bold correspond to 